\title{
Structural Diversification of Andiconin-Derived Natural Products by $\alpha$-Ketoglutarate-Dependent Dioxygenases
}

Tongxuan Bai, ${ }^{\dagger, \star}$ Y Ydai Matsuda, ${ }^{\S}, * *$ Hui Tao, ${ }^{\dagger}$ Takahiro Mori, ${ }^{\dagger}, \uparrow$ Yonghui Zhang, ${ }^{\sharp}$ and Ikuro $\mathrm{Abe}^{\dagger, \uparrow, *}$

${ }^{\dagger}$ Graduate School of Pharmaceutical Sciences, The University of Tokyo, 7-3-1 Hongo, Bunkyo-ku, Tokyo 113-0033, Japan.

${ }^{\S}$ Department of Chemistry, City University of Hong Kong, Tat Chee Avenue, Kowloon, Hong Kong SAR, China

'Collaborative Research Institute for Innovative Microbiology, The University of Tokyo, Yayoi 1-1-1, Bunkyo-ku, Tokyo 113-8657, Japan

\#Hubei Key Laboratory of Natural Medicinal Chemistry and Resource Evaluation, School of Pharmacy, Tongji Medical College, Huazhong University of Science and Technology, Wuhan 430030, China

\section{Table of Contents}

Supplementary Material and Methods

Supplementary Tables S1-S11

Supplementary Figures S1-S22 


\section{Supplementary Materials and Methods}

\section{General}

Solvents and chemicals were purchased from Wako Chemicals Ltd. (Tokyo, Japan) or Kanto Chemical Co., Inc. (Tokyo, Japan), unless noted otherwise. Oligonucleotide primers were purchased from Eurofins Genetics or Sigma-Aldrich., and are listed in Table S2. PCR was performed using a TaKaRa PCR Thermal Cycler Dice ${ }^{\circledR}$ Gradient (TaKaRa) with iProof DNA polymerase (BIO-RAD) or KOD FX Neo (TOYOBO). Sequence analyses were performed by Eurofins Genetics (Tokyo). Analytical and preparative HPLC were performed on a Shimadzu Prominence system. Silica gel column chromatography was performed using Silica Gel 60 N (spherical, neutral). NMR spectra were obtained at $500 \mathrm{MHz}\left({ }^{1} \mathrm{H}\right) / 125 \mathrm{MHz}\left({ }^{13} \mathrm{C}\right)$ with a JEOL ECX-500 or ECZ-500 spectrometer or at $900 \mathrm{MHz}$ $\left({ }^{1} \mathrm{H}\right) / 225 \mathrm{MHz}\left({ }^{13} \mathrm{C}\right)$ with a Bruker Avance III HD $900 \mathrm{MHz}$ NMR spectrometer at RIKEN Yokohama, and chemical shifts were recorded with reference to solvent signals $\left({ }^{1} \mathrm{H} N \mathrm{NR}\right.$ : $\mathrm{CDCl}_{3} 7.26 \mathrm{ppm}, \mathrm{CD}_{3} \mathrm{OD}$ $3.34 \mathrm{ppm} ;{ }^{13} \mathrm{C}$ NMR: $\left.\mathrm{CDCl}_{3} 77.2 \mathrm{ppm}, \mathrm{CD}_{3} \mathrm{OD} 49.1 \mathrm{ppm}\right)$. Structural assignments were made with additional information from gCOSY, gHMQC, gHMBC, and NOESY experiments for new compounds. Samples for LC-HR-MS/MS analysis were injected into a Shimadzu Prominence LC-20AD system with a compact mass spectrometer (Bruker Daltonics), using electrospray ionization with a COSMOSIL 2.5C18-MS-II column (2.0 i.d. $\times 75 \mathrm{~mm}$; Nacalai Tesque, Inc.).

\section{Strains and media}

Aspergillus sp. TJ23 was obtained previously, ${ }^{1}$ and was cultivated at $30{ }^{\circ} \mathrm{C}, 160 \mathrm{rpm}$ in DPY medium (2\% dextrin, $1 \%$ hipolypepton (Nihon Pharmaceutical Co., Ltd.), 0.5\% yeast extract (Difco), 0.5\% $\mathrm{KH}_{2} \mathrm{PO}_{4}$, and $0.05 \% \mathrm{MgSO}_{4} \cdot 7 \mathrm{H}_{2} \mathrm{O}$ ) for 3 days, and used as the source for the cloning of several genes in the spiroaspertrione A biosynthetic gene cluster. Aspergillus oryzae NSAR1/andMKDEBCA2 was used as the host for fungal expression. Transformants of the A. oryzae strain were grown in shaking cultures in DPY medium for three-five days, at $30{ }^{\circ} \mathrm{C}$ and $160 \mathrm{rpm}$. Standard DNA engineering experiments were performed using Escherichia coli DH5 $\alpha$, purchased from Clontech (Mountain View, CA). E. coli Rosetta ${ }^{\mathrm{TM}} 2$ (DE3)pLysS (Novagen) was used for the expression of SptF, SptG, and SptN. E. coli cells bearing each plasmid were grown in Luria-Bertani medium and were selected with ampicillin or kanamycin or kanamycin with chloramphenicol.

\section{Whole genome sequencing and analysis}

The whole-genome sequencing and assembling of Aspergillus sp. TJ23 was performed by Macrogen Japan (Kyoto, Japan), yielding 111 contigs covering approximately $33.4 \mathrm{Mb}$. Gene prediction was then 
performed using AUGUSTUS (http://bioinf.uni-greifswald.de/webaugustus/), and manually revised according to the homologous genes found in the NCBI database, if necessary.

\section{Construction of fungal expression plasmids}

For the construction of the fungal expression plasmid with $s p t I$ and $s p t G$, these gene were first amplified from Aspergillus sp. TJ23 genomic DNA, with the primers listed in Tables S2 and S3. The full-length $s p t I$ and $s p t G$ genes were purified, and ligated into the pTAex $3^{3}$ vector using an In-Fusion ${ }^{\circledR}$ HD Cloning Kit (Clontech), according to the manufacturer's protocol (Table S3). For the introduction of the two genes into pPTRI, ${ }^{4}$ the DNA fragments with the $a m y B$ promoter (PamyB) and the $a m y B$ terminator $($ Tamy $B)$ were amplified from the pTAex3-based plasmids and ligated into the promoter/terminatorfree vectors, using an In-Fusion ${ }^{\circledR}$ HD Cloning Kit, as summarized in Table S3. To construct pPTRIsptI+andG, the DNA fragment with and $G$ gene was amplified from the plasmid pTAex3-andG constructed in our previous work ${ }^{2}$ (Table S3).

\section{Transformation of Aspergillus oryzae NSAR1/andMKDEBCA}

Transformation of $A$. oryzae NSAR1/andMKDEBCA was performed by the protoplast-polyethylene glycol method, as reported previously. ${ }^{5}$ Transformants of $A$. oryzae constructed in this study are listed in Table S4.

\section{HPLC analysis of products of $A$. oryzae transformants}

Products from A. oryzae transformants were analyzed by HPLC using TSKgel ODS-80TsQA column (4.6 i.d. x $150 \mathrm{~mm}$; Tosoh Co. Ltd.), with a solvent system of $0.5 \%$ acetic acid (solvent A) and acetonitrile containing $0.5 \%$ acetic acid (solvent B), at a flow rate of $1.0 \mathrm{ml} / \mathrm{min}$ and a column temperature of $40{ }^{\circ} \mathrm{C}$. Separation was performed with solvent B/solvent A (20:80) for 5 min, a linear gradient from 20:80 to 100:0 within the following $20 \mathrm{~min}$, 100:0 for 5 additional min, and a linear gradient from 100:0 to 20:80 within the following $3 \mathrm{~min}$.

\section{Isolation and purification of each metabolite from $A$. oryzae transformants}

For the isolation of each metabolite, $2 \mathrm{~L}$ of the culture media were extracted with ethyl acetate. Mycelia were extracted with acetone at room temperature for 2 hours, concentrated, and re-extracted with ethyl acetate. Both extracts were combined and subjected to silica-gel column chromatography and further purified by preparative HPLC. The detailed purification procedure is described below.

\section{Purification conditions for andiconin B (2):}


The medium extract from a $2 \mathrm{~L}$ culture of $A$. oryzae/andMKDEBCA+sptI+spt $G$ was subjected to silicagel column chromatography, and eluted stepwise with a chloroform:methanol gradient (100:0 to 90:10).

Fractions that contained 2 were further purified by reverse-phase preparative HPLC (60\% aqueous acetonitrile, $3.0 \mathrm{~mL} / \mathrm{min}$ ) with YMC-Triart C18 column (10 i.d. x $250 \mathrm{~mm}$; YMC CO., LTD.) to yield $11.2 \mathrm{mg}$ of a colorless solid.

\section{Purification conditions for andiconin D (3):}

The medium extract from a $2 \mathrm{~L}$ culture of $A$. oryzae/andMKDEBCA+sptI+and $G$ was subjected to silicagel column chromatography, and eluted stepwise with a chloroform:methanol gradient (100:0 to 90:10). Fractions that contained 3 were further purified by reverse-phase preparative HPLC (70\% aqueous acetonitrile, $3.0 \mathrm{~mL} / \mathrm{min}$ ) with YMC-Triart C18 column (10 i.d. x $250 \mathrm{~mm}$; YMC CO., LTD.) to yield $6.0 \mathrm{mg}$ of a white solid.

\section{Expression and purification of the Spt enzymes}

The full-length $s p t F, s p t N$, and $s p t G$ genes were amplified from the Aspergillus sp. TJ23 genomic DNA, with the primers listed in Tables S2 and S3, and individually ligated into the pET-28a(+) vector linearized by $N d e$ I and HindIII using an In-Fusion ${ }^{\circledR}$ HD Cloning Kit to yield the E. coli expression vectors pET-28a(+)-sptN, pET-28a(+)-sptF, and pET-28a(+)-sptG, respectively. For the protein expression, E. coli Rosetta $^{\mathrm{TM}} 2$ (DE3)pLysS was transformed with the constructed plasmids. Each transformant was incubated in LB medium supplemented with $25 \mathrm{mg} / \mathrm{L}$ chloramphenicol and 50 $\mathrm{mg} / \mathrm{L}$ kanamycin sulfate, at $37{ }^{\circ} \mathrm{C} / 200 \mathrm{rpm}$. Gene expression was induced by the addition of $0.3 \mathrm{mM}$ IPTG when the $\mathrm{OD}_{600}$ reached 0.6 , followed by further incubation with shaking at $200 \mathrm{rpm}$ at $16{ }^{\circ} \mathrm{C}$ for $20 \mathrm{~h}$. The cells were harvested by centrifugation, resuspended in lysis buffer $(20 \mathrm{mM}$ Tris-HCl, 200 $\mathrm{mM} \mathrm{NaCl}, 5 \mathrm{mM}$ imidazole, $5 \%$ glycerol, $\mathrm{pH} 7.5$ ), and lysed on ice by sonication. After centrifugation, the supernatant was applied to a Ni-NTA affinity column, which was washed with 50 column volumes of wash buffer (20 mM Tris-HCl, $200 \mathrm{mM} \mathrm{NaCl}, 20 \mathrm{mM}$ imidazole, 5\% glycerol, $\mathrm{pH}$ 7.5). The Histagged protein was eluted with 5 column volumes of elution buffer ( $20 \mathrm{mM}$ Tris- $\mathrm{HCl}, 200 \mathrm{mM} \mathrm{NaCl}$, $300 \mathrm{mM}$ imidazole, 5\% glycerol, pH 7.5). The purified enzymes were analyzed by sodium dodecyl sulfate polyacrylamide gel electrophoresis (SDS-PAGE) (Figure S4). The protein concentrations of $\mathrm{SptF}$, SptN, and SptG were determined using a Nanodrop spectrometer (GE healthcare Life Science) at $280 \mathrm{~nm}$ using the estimated extinction coefficient of $52160 \mathrm{M}^{-1} \mathrm{~cm}^{-1}, 49180 \mathrm{M}^{-1} \mathrm{~cm}^{-1}$, and $61600 \mathrm{M}^{-1}$ $\mathrm{cm}^{-1}$, respectively.

\section{Enzymatic reaction assay of SptF and SptN}


The enzymatic reactions were performed in a $100 \mu \mathrm{L}$ reaction mixture, containing $50 \mathrm{mM}$ PIPES (pH 7.5), $200 \mu \mathrm{M} \mathrm{FeSO}_{4}, 0.1 \mathrm{mM}$ of substrate, $5 \mathrm{mM} \alpha$-ketoglutarate, $4 \mathrm{mM}$ ascorbate, and $10 \mu \mathrm{M}$ of SptF and/or SptN. The reaction was incubated at $30^{\circ} \mathrm{C}$ for 2 hours or overnight. The reaction was then quenched by adding $50 \mu \mathrm{L}$ of methanol. After filtration, the products from each reaction were analyzed by HPLC ( $40 \%$ to $100 \%$ aqueous acetonitrile for $20 \mathrm{~min}, 1.0 \mathrm{~mL} / \mathrm{min})$ with a TSKgel ODS-80TsQA column (4.6 i.d. x $150 \mathrm{~mm}$; Tosoh Co. Ltd.).

\section{Enzymatic reaction assay of SptG}

The enzymatic reaction of SptG with andiconin B (2) was performed in a reaction mixture containing $50 \mathrm{mM}$ Tris-HCl buffer (pH 7.5), $500 \mu \mathrm{M}$ of $2,2 \mathrm{mM}$ acetyl coenzyme A, and $8.6 \mu \mathrm{M} \mathrm{SptG}$, in a final volume of $100 \mu \mathrm{L}$. After an incubation at $30^{\circ} \mathrm{C}$ for $3 \mathrm{~h}$, the reaction was terminated by adding $50 \mu \mathrm{L}$ of methanol and mixed by vortex. After filtration, the products from each reaction were analyzed by HPLC (30\% to $100 \%$ aqueous acetonitrile for $20 \mathrm{~min}, 1.0 \mathrm{~mL} / \mathrm{min})$ with a TSKgel ODS-80TsQA column (4.6 i.d. x $150 \mathrm{~mm}$; Tosoh Co. Ltd.).

\section{Isolation and purification of products from in vitro enzymatic reactions}

To obtain 4 and 5, enzymatic reaction of SptF with andiconin D (3) was performed in a $50 \mathrm{~mL}$ of reaction mixture. The enzyme reaction products were extracted by ethyl acetate and resolved in methanol, and then purified by preparative HPLC ( $45 \%$ aqueous acetonitrile, $3.0 \mathrm{~mL} / \mathrm{min}$ ) with a COSMOSIL 5C $\mathrm{C}_{18}$-PAQ column (10 mm i.d. $\times 250 \mathrm{~mm}$; Nacalai Tesque, Inc.) to yield $1.29 \mathrm{mg}$ of $\mathbf{4}$ and $0.69 \mathrm{mg}$ of 5 .

To obtain 6, enzymatic reaction of $\mathrm{SptN}$ with andiconin $\mathrm{D}(\mathbf{3})$ was performed in a $50 \mathrm{~mL}$ of reaction mixture. The enzyme reaction product was extracted by ethyl acetate and resolved in methanol, and then purified by preparative HPLC (50\% aqueous acetonitrile, $3.0 \mathrm{~mL} / \mathrm{min})$ with a COSMOSIL $5 \mathrm{C}_{18^{-}}$ PAQ column (10 mm i.d. $\times 250 \mathrm{~mm}$; Nacalai Tesque, Inc.) to yield $1.23 \mathrm{mg}$ of $\mathbf{6}$.

To obtain 7 and 8, enzymatic reaction of $\mathrm{SptF}$ and $\mathrm{SptN}$ with andiconin D (3) was performed in a 50 $\mathrm{mL}$ of reaction mixture. The enzyme reaction products were extracted by ethyl acetate and resolved in methanol, and then purified by preparative HPLC (30\% to 100\% aqueous acetonitrile for $22 \mathrm{~min}, 3.0$ $\mathrm{mL} / \mathrm{min})$ with a COSMOSIL $5 \mathrm{C}_{18}$-PAQ column $(10 \mathrm{~mm}$ i.d. $\times 250 \mathrm{~mm}$; Nacalai Tesque, Inc. $)$ to yield $1.77 \mathrm{mg}$ of 7 and $0.28 \mathrm{mg}$ of 8 .

\section{Analytical data}

Andiconin B (2). Colorless solid; $[\alpha]^{24}-22.0\left(c 0.10, \mathrm{CH}_{3} \mathrm{OH}\right)$; for NMR data see Table S5 and Figures $\mathrm{S} 5$ and S6; HRMS (ESI) $m / z$ : $[\mathrm{M}+\mathrm{H}]^{+}$Calcd for $\mathrm{C}_{25} \mathrm{H}_{33} \mathrm{O}_{5}$ 413.2323; Found 413.2324. The NMR data were in good agreement with the reported data. ${ }^{1}$ 
Andiconin D (3). White solid; $[\alpha]^{24} \mathrm{D}-220.0\left(c 0.05, \mathrm{CH}_{3} \mathrm{OH}\right)$; for NMR data see Table S6 and Figures S7 to S12; HRMS (ESI) $m / z$ : $[\mathrm{M}+\mathrm{H}]^{+}$Calcd for $\mathrm{C}_{25} \mathrm{H}_{31} \mathrm{O}_{4}$ 395.2217; Found 395.2221.

Emervaridone B (4). White solid; $[\alpha]^{24}-91.8\left(c 0.11, \mathrm{CH}_{3} \mathrm{OH}\right)$; for NMR data see Table $\mathrm{S} 7$ and Figures $\mathrm{S} 13$ and S14; HRMS (ESI) $m / z$ : $[\mathrm{M}+\mathrm{H}]^{+}$Calcd for $\mathrm{C}_{25} \mathrm{H}_{29} \mathrm{O}_{4}$ 393.2060; Found 393.2064. The NMR data were in good agreement with the reported data. ${ }^{6}$

Emervaridone $\boldsymbol{C}$ (5). Colorless solid; $[\alpha]^{24}-73.8\left(c\right.$ 0.05, $\left.\mathrm{CH}_{3} \mathrm{OH}\right)$; for NMR data see Table S8 and Figures S15 and S16; HRMS (ESI) $m / z$ : $[\mathrm{M}+\mathrm{H}]^{+}$Calcd for $\mathrm{C}_{25} \mathrm{H}_{29} \mathrm{O}_{5}$ 409.2010; Found 409.2017. The NMR data were in good agreement with the reported data. ${ }^{6}$

Emeridone A (6'). White solid; $[\alpha]^{24}-4.0\left(c 0.10, \mathrm{CH}_{2} \mathrm{Cl}_{2}\right)$; for NMR data see Table S9 and Figures $\mathrm{S} 17$ and S18; HRMS (ESI) $m / z$ : $[\mathrm{M}+\mathrm{H}]^{+}$Calcd for $\mathrm{C}_{25} \mathrm{H}_{31} \mathrm{O}_{5}$ 411.2166; Found 411.2160. The NMR data were in good agreement with the reported data. ${ }^{7}$

Emervaridione (7). White solid; $[\alpha]^{24}-77.0\left(c 0.15, \mathrm{CH}_{3} \mathrm{OH}\right)$; for NMR data see Table $\mathrm{S} 10$ and Figures $\mathrm{S} 19$ and S20; HRMS (ESI) $m / z$ : $[\mathrm{M}+\mathrm{H}]^{+}$Calcd for $\mathrm{C}_{25} \mathrm{H}_{29} \mathrm{O}_{5}$ 409.2010; Found 409.2003. The NMR data were in good agreement with the reported data. ${ }^{8}$

Emeridone F (8). Colorless solid; $[\alpha]^{24}{ }_{\mathrm{D}}-2.6\left(c \mathrm{c} 0.15, \mathrm{CH}_{2} \mathrm{Cl}_{2}\right)$; for NMR data see Table $\mathrm{S} 11$ and Figures $\mathrm{S} 21$ to S22; HRMS (ESI) $m / z$ : [M + H] $]^{+}$Calcd for $\mathrm{C}_{25} \mathrm{H}_{29} \mathrm{O}_{6}$ 425.1959; Found 425.1961. The NMR data were in good agreement with the reported data. ${ }^{7}$ 
Table S1. Annotation of each gene in the spt cluster.

\begin{tabular}{ccccc} 
Gene & Amino acids (base pairs) & Protein homologue [origin] & Similarity/identity (\%) & Proposed function \\
\hline$s p t A$ & $293(882)$ & AndA [Emericella variecolor] & $100 / 99$ & Fe(II)/aKG-dependent dioxygenase \\
$s p t B$ & $236(782)$ & AndB [Emericella variecolor] & $99 / 99$ & terpene cyclase \\
$s p t C$ & $255(940)$ & AndC [Emericella variecolor] & $98 / 98$ & short-chain dehydrogenase/reductase \\
$s p t D$ & $237(984)$ & AndD [Emericella variecolor] & $100 / 99$ & prenyltransferase \\
$s p t E$ & $471(1564)$ & AndE [Emericella variecolor] & $99 / 98$ & FAD-dependent monooxygenase \\
$s p t G$ & $477(1434)$ & AndG [Emericella variecolor] & $63 / 45$ & acetyltransferase \\
$s p t F$ & $285(858)$ & AndF [Emericella variecolor] & $96 / 94$ & Fe(II)/aKG-dependent dioxygenase \\
$s p t N$ & $290(873)$ & AndF [Emericella variecolor] & $67 / 50$ & Fe(II)/aKG-dependent dioxygenase \\
$s p t I$ & $290(923)$ & AndI [Emericella variecolor] & $80 / 61$ & short-chain dehydrogenase/reductase \\
$s p t K$ & $867(2943)$ & AndK [Emericella variecolor] & $96 / 95$ & cytochrome P450 monooxygenase/hydrolase \\
$s p t L$ & $177(687)$ & AndL [Emericella variecolor] & $99 / 99$ & hypothetical protein \\
$s p t M$ & $2430(7499)$ & AndM [Emericella variecolor] & $99 / 99$ & polyketide synthase
\end{tabular}

Table S2. Primers used in this study.

\begin{tabular}{l|l} 
Primer & Sequence (5' to 3') \\
\hline Sptl-F & TCGAGCTCGGTACCCATGACTGATCCTGCATCCCA \\
Sptl-R & CTACTACAGATCCCCTGCTCGAGATAACAACTCCC \\
SptG-F & TCGAGCTCGGTACCCATGGCGTTAGGCGCGTTAC \\
SptG-R & CTACTACAGATCCCCTCACTCTAGCAAGAACCGAA \\
SptF-F & CGCGGCAGCCATATGATGACCGTTCCCCAAC \\
SptF-R & CTCGAATTCGGATCCTTACGCAGCAACGGAC \\
SptN-F & CCGCGCGGCAGCCATATGACCGTTGCAGCAGAC \\
SptN-R & CTCGAATTCGGATCCTACACTGCAGACTTCAAACC \\
SptG-F2 & CGCGCGGCAGCCATATGATGGCGTTAGGCGC \\
SptG-R2 & GTGCGGCCGCAAGCTTTCACTCTAGCAAGAACC \\
InF-pPTRI_HindIII-F & TGATTACGCCAAGCTCCCATCATGGTGTTTTGATC \\
InF-pPTRI_HindIII-R & GCAGGCATGCAAGCTGTAAGATACATGAGCTTCGG \\
InF-linker-F1 & GCTCGCGAGCGCGTTCCACTGCATCATCAGTCTAG \\
InF-linker-R1 & AACGCGCTCGCGAGCAAGTACCATACAGTACCGCG
\end{tabular}

Table S3. Plasmids constructed in this study and PCR / ligation conditions.

\begin{tabular}{|c|c|c|c|c|c|c|}
\hline Plasmid & Insert & Vector & Primer 1 & Primer 2 & PCR template & Ligation method \\
\hline pTAex3-sptl & sptl & pTAex3 digested with Smal & Sptl-F & Sptl-R & gDNA & In-Fusion ${ }^{\circledast D}$ Cloning Kit \\
\hline pTAex3-sptG & sptG & pTAex3 digested with Smal & SptG-F & SptG-R & gDNA & In-Fusion ${ }^{\mathscr{B} D}$ Cloning Kit \\
\hline \multirow{2}{*}{ pPTRI-sptl+sptG } & PamyB-sptl-TamyB & \multirow{2}{*}{ pPTRI digested with Hind III } & InF-pPTRI_HindIII-F & InF-linker-R1 & pTAex3-sptl & \multirow{2}{*}{ In-Fusion ${ }^{\circledast}$ HD Cloning Kit } \\
\hline & PamyB-sptG-TamyB & & InF-linker-F1 & InF-pPTRI_HindllI-R & pTAex3-sptG & \\
\hline \multirow{2}{*}{ pPTRI-sptl+andG } & PamyB-sptl-TamyB & \multirow{2}{*}{ pPTRI digested with Hind III } & InF-pPTRI_HindIII-F & InF-linker-R1 & pTAex3-sptl & \multirow{2}{*}{ In-Fusion ${ }^{\circledast}$ HD Cloning Kit } \\
\hline & PamyB-andG-TamyB & & InF-linker-F1 & InF-pPTRI_Hindlll-R & pTAex3-andG & \\
\hline pET28a(+)-sptF & sptF & pET28a(+) digested with $\mathrm{Ndel}$ and Hind IIII & SptF-F & SptF-R & gDNA & In-Fusion ${ }^{\oplus D}$ Cloning Kit \\
\hline pET28a(+)-sptN & sptN & pET28a(+) digested with $\mathrm{Ndel}$ and Hind IIII & SptN-F & SptN-R & gDNA & In-Fusion ${ }^{10}$ Cloning Kit \\
\hline pET28a(+)-sptG & sptG & pET28a $(+)$ digested with $N d e I$ and Hind III & SptG-F2 & SptG-R2 & gDNA & In-Fusion ${ }^{10}$ HD Cloning Kit \\
\hline
\end{tabular}

Table S4. A. oryzae transformants constructed in this study.

\begin{tabular}{l|c|c} 
Strain & Host strain & Plasmids used for transformation \\
\hline A. oryzae/andMKDEBCA + sptl+sptG & A. oryzae/andMKDEBCA & pPTRI-sptl+sptG \\
A. oryzae/andMKDEBCA +spt/+andG & A. oryzae/andMKDEBCA & pPTRI-sptl+andG
\end{tabular}




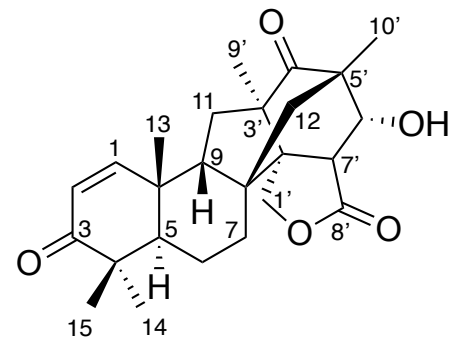

Table S5. NMR data for andiconin B (2).

\begin{tabular}{|c|c|c|c|c|}
\hline \multirow[b]{2}{*}{ position } & \multirow{2}{*}{$\begin{array}{c}{ }^{13} \mathrm{C} \\
\delta(\mathrm{ppm})\end{array}$} & \multicolumn{3}{|c|}{${ }^{1} \mathrm{H}$} \\
\hline & & $\delta(p p m)$ & intensitiy & multiplicity \\
\hline 1 & 157.6 & 6.55 & $1 \mathrm{H}$ & $\mathrm{d}(J=10.1 \mathrm{~Hz})$ \\
\hline 2 & 125.9 & 5.81 & $1 \mathrm{H}$ & $\mathrm{d}(J=10.1 \mathrm{~Hz})$ \\
\hline 3 & 206.6 & & & \\
\hline 4 & 45.4 & & & \\
\hline 5 & 39.7 & 1.42 & $1 \mathrm{H}$ & $\mathrm{m}$ \\
\hline \multirow[t]{2}{*}{6} & 19.4 & 1.82 & $1 \mathrm{H}$ & $\mathrm{m}$ \\
\hline & & 1.71 & $1 \mathrm{H}$ & $\mathrm{m}$ \\
\hline \multirow[t]{2}{*}{7} & 25.0 & 2.06 & $1 \mathrm{H}$ & $\mathrm{m}$ \\
\hline & & 1.82 & $1 \mathrm{H}$ & $\mathrm{m}$ \\
\hline 8 & 46.7 & & & \\
\hline 9 & 56.6 & 1.57 & $1 \mathrm{H}$ & $\mathrm{m}$ \\
\hline 10 & 39.9 & & & \\
\hline \multirow[t]{2}{*}{11} & 39.8 & 1.71 & $1 \mathrm{H}$ & $\mathrm{m}$ \\
\hline & & 1.28 & $1 \mathrm{H}$ & $\mathrm{m}$ \\
\hline \multirow[t]{2}{*}{12} & 51.7 & 1.57 & $1 \mathrm{H}$ & $\mathrm{m}$ \\
\hline & & 1.13 & $1 \mathrm{H}$ & $\mathrm{m}$ \\
\hline 13 & 23.1 & 1.27 & $3 \mathrm{H}$ & $\mathrm{s}$ \\
\hline 14 & 23.9 & 1.11 & $3 \mathrm{H}$ & s \\
\hline 15 & 17.4 & 1.04 & $3 \mathrm{H}$ & $s$ \\
\hline \multirow[t]{2}{*}{$1^{\prime}$} & 70.3 & 4.32 & $1 \mathrm{H}$ & $\mathrm{d}(J=9.4 \mathrm{~Hz})$ \\
\hline & & 4.15 & $1 \mathrm{H}$ & $\mathrm{d}(J=9.4 \mathrm{~Hz})$ \\
\hline $2^{\prime}$ & 58.3 & & & \\
\hline $3^{\prime}$ & 56.6 & & & \\
\hline $4^{\prime}$ & 219.6 & & & \\
\hline $5^{\prime}$ & 51.3 & & & \\
\hline $6^{\prime}$ & 73.4 & 4.01 & $1 \mathrm{H}$ & $\mathrm{d}(J=7.1 \mathrm{~Hz})$ \\
\hline $7^{\prime}$ & 42.5 & 3.23 & $1 \mathrm{H}$ & $\mathrm{d}(J=7.1 \mathrm{~Hz})$ \\
\hline $8^{\prime}$ & 176.6 & & & \\
\hline $9^{\prime}$ & 16.4 & 1.11 & $3 \mathrm{H}$ & s \\
\hline $10^{\prime}$ & 21.9 & 1.05 & $3 \mathrm{H}$ & $\mathrm{s}$ \\
\hline
\end{tabular}

${ }^{1} \mathrm{H}$ NMR: $500 \mathrm{MHz},{ }^{13} \mathrm{C}$ NMR: $125 \mathrm{MHz}$ (in $\mathrm{CD}_{3} \mathrm{OD}$ ) 


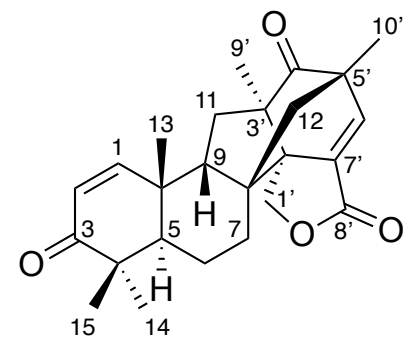

Table S6. NMR data for andiconin D (3).

\begin{tabular}{|c|c|c|c|c|c|c|c|}
\hline \multirow[b]{2}{*}{ position } & \multirow{2}{*}{$\begin{array}{c}{ }^{13} \mathrm{C} \\
\delta(\mathrm{ppm})\end{array}$} & \multicolumn{6}{|c|}{${ }^{1} \mathrm{H}$} \\
\hline & & $\delta(\mathrm{ppm})$ & intensitiy & multiplicity & HMBC correlation & COSY correlation & NOESY correlation \\
\hline 1 & 154.0 & 6.34 & $1 \mathrm{H}$ & $\mathrm{d}(\mathrm{J}=10.2 \mathrm{~Hz})$ & $3,5,9$ & $\mathrm{H}-2$ & $\mathrm{H}-2, \mathrm{H}-9, \mathrm{H}-13$ \\
\hline 2 & 125.8 & 5.89 & $1 \mathrm{H}$ & $\mathrm{d}(J=10.2 \mathrm{~Hz})$ & 4,5 & $\mathrm{H}-1$ & $\mathrm{H}-1$ \\
\hline 3 & 203.8 & & & & & & \\
\hline 4 & 44.3 & & & & & & \\
\hline 5 & 39.4 & 1.34 & $1 \mathrm{H}$ & $\operatorname{dd}(J=11.5,7.5 \mathrm{~Hz})$ & $4,6,10,15$ & $\mathrm{H}-6$ & $\mathrm{H}-11 \mathrm{a}, \mathrm{H}-14, \mathrm{H}-1^{\prime} \mathrm{a}, \mathrm{H}-1^{\prime} \beta$ \\
\hline 6 & 18.7 & 1.82 & $2 \mathrm{H}$ & $\mathrm{m}$ & 7 & $\mathrm{H}-5, \mathrm{H}-7 \mathrm{a}, \mathrm{H}-7 \beta$ & \\
\hline \multirow[t]{2}{*}{7} & 27.7 & $1.69(a)$ & $1 \mathrm{H}$ & $\mathrm{m}$ & $8,12,2^{\prime}$ & $H-7 \beta$ & $H-1^{\prime} \beta$ \\
\hline & & $1.87(\beta)$ & $1 \mathrm{H}$ & $\mathrm{m}$ & $6,2^{\prime}$ & $H-7 a$ & $\mathrm{H}-12 \beta, \mathrm{H}-13$ \\
\hline 8 & 47.3 & & & & & & \\
\hline 9 & 57.4 & 1.69 & $1 \mathrm{H}$ & $\mathrm{m}$ & $5,8,12,13,2^{\prime}$ & & $\mathrm{H}-1, \mathrm{H}-12 \mathrm{a}, \mathrm{H}-13$ \\
\hline 10 & 38.6 & & & & & & \\
\hline \multirow[t]{2}{*}{11} & 36.6 & $1.02(a)$ & $1 \mathrm{H}$ & $\mathrm{dd}(J=16.1,14.4 \mathrm{~Hz})$ & $8,9,10,2^{\prime}, 3^{\prime}, 4^{\prime}, 9^{\prime}$ & $\mathrm{H}-9, \mathrm{H}-11 \beta$ & $\mathrm{H}-5, \mathrm{H}-1^{\prime} \mathrm{a}$ \\
\hline & & $1.69(\beta)$ & $1 \mathrm{H}$ & $\mathrm{m}$ & $3^{\prime}$ & $H-9, H-11 a$ & \\
\hline \multirow[t]{2}{*}{12} & 58.0 & $1.57(a)$ & $1 \mathrm{H}$ & $\mathrm{d}(\mathrm{J}=12.3 \mathrm{~Hz})$ & $9,2^{\prime}, 5^{\prime}, 6^{\prime}, 10^{\prime}$ & $\mathrm{H}-12 \beta$ & $\mathrm{H}-9$ \\
\hline & & $1.46(\beta)$ & $1 \mathrm{H}$ & $\mathrm{d}(J=12.3 \mathrm{~Hz})$ & $7,8,9,4^{\prime}, 5^{\prime}, 6^{\prime}, 10^{\prime}$ & $H-12 a$ & $\mathrm{H}-7 \beta$ \\
\hline 13 & 23.0 & 1.28 & $3 \mathrm{H}$ & $\mathrm{s}$ & $1,5,9,10$ & & $\mathrm{H}-1, \mathrm{H}-7 \beta, \mathrm{H}-9, \mathrm{H}-15$ \\
\hline 14 & 23.7 & 1.15 & $3 \mathrm{H}$ & s & $3,4,5,15$ & & $\mathrm{H}-5$ \\
\hline 15 & 21.4 & 1.06 & $3 \mathrm{H}$ & $\mathrm{s}$ & $3,4,5,14$ & & $\mathrm{H}-13$ \\
\hline \multirow[t]{2}{*}{$1^{\prime}$} & 69.0 & $4.35(a)$ & $1 \mathrm{H}$ & $\mathrm{d}(J=10.3 \mathrm{~Hz})$ & $3^{\prime}, 8^{\prime}$ & $H-1^{\prime} \beta$ & $\mathrm{H}-5, \mathrm{H}-9^{\prime}, \mathrm{H}-11 \mathrm{a}$ \\
\hline & & $4.47(\beta)$ & $1 \mathrm{H}$ & $\mathrm{d}(J=10.3 \mathrm{~Hz})$ & $8,2^{\prime}, 3^{\prime}$ & $\mathrm{H}-1^{\prime} \mathrm{a}$ & $\mathrm{H}-5, \mathrm{H}-7 \mathrm{a}$ \\
\hline $2^{\prime}$ & 60.3 & & & & & & \\
\hline $3^{\prime}$ & 53.7 & & & & & & \\
\hline $4^{\prime}$ & 214.4 & & & & & & \\
\hline $5^{\prime}$ & 51.7 & & & & & & \\
\hline $6^{\prime}$ & 143.6 & 7.14 & $1 \mathrm{H}$ & $\mathrm{s}$ & $2^{\prime}, 5^{\prime}, 8^{\prime}, 10^{\prime}$ & & $\mathrm{H}-10^{\prime}$ \\
\hline $7^{\prime}$ & 133.9 & & & & & & \\
\hline $8^{\prime}$ & 167.2 & & & & & & \\
\hline $9^{\prime}$ & 16.7 & 0.97 & $3 \mathrm{H}$ & $\mathrm{s}$ & $11,2^{\prime}, 3^{\prime}, 4^{\prime}$ & & \\
\hline $10^{\prime}$ & 17.2 & 1.34 & $3 \mathrm{H}$ & $s$ & $12,4^{\prime}, 5^{\prime}, 6^{\prime}$ & & $\mathrm{H}-6^{\prime}$ \\
\hline
\end{tabular}

${ }^{1} \mathrm{H}$ NMR: $500 \mathrm{MHz},{ }^{13} \mathrm{C}$ NMR: $125 \mathrm{MHz}$ (in $\mathrm{CDCl}_{3}$ ) 


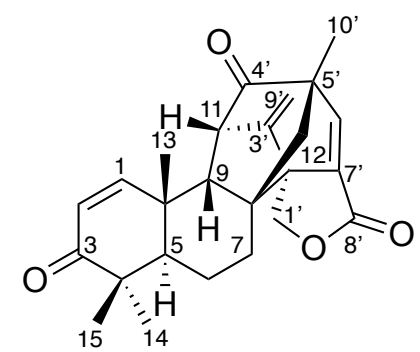

Table S7. NMR data for emervaridone B (4).

\begin{tabular}{|c|c|c|c|c|}
\hline \multirow[b]{2}{*}{ position } & \multirow{2}{*}{$\begin{array}{c}{ }^{13} \mathrm{C} \\
\delta(\mathrm{ppm})\end{array}$} & \multicolumn{3}{|c|}{${ }^{1} \mathrm{H}$} \\
\hline & & $\delta(p p m)$ & intensitiy & multiplicity \\
\hline 1 & 151.7 & 6.55 & $1 \mathrm{H}$ & $\mathrm{d}(J=10.2 \mathrm{~Hz})$ \\
\hline 2 & 126.2 & 5.89 & $1 \mathrm{H}$ & $\mathrm{d}(\mathrm{J}=10.2 \mathrm{~Hz})$ \\
\hline 3 & 203.2 & & & \\
\hline 4 & 44.6 & & & \\
\hline 5 & 41.4 & 1.86 & $1 \mathrm{H}$ & $\mathrm{m}$ \\
\hline \multirow[t]{2}{*}{6} & 17.0 & 1.82 & $1 \mathrm{H}$ & $\mathrm{m}$ \\
\hline & & 1.58 & $1 \mathrm{H}$ & $\mathrm{m}$ \\
\hline \multirow[t]{2}{*}{7} & 26.1 & 2.03 & $1 \mathrm{H}$ & $\mathrm{m}$ \\
\hline & & 1.91 & $1 \mathrm{H}$ & $\mathrm{m}$ \\
\hline 8 & 48.2 & & & \\
\hline 9 & 60.7 & 1.78 & $1 \mathrm{H}$ & $\mathrm{m}$ \\
\hline 10 & 37.8 & & & \\
\hline 11 & 68.4 & 3.71 & $1 \mathrm{H}$ & $s$ \\
\hline \multirow[t]{2}{*}{12} & 55.4 & 1.70 & $1 \mathrm{H}$ & $\mathrm{m}$ \\
\hline & & 1.62 & $1 \mathrm{H}$ & $\mathrm{m}$ \\
\hline 13 & 26.1 & 1.28 & $3 \mathrm{H}$ & $\mathrm{s}$ \\
\hline 14 & 24.5 & 1.13 & $3 \mathrm{H}$ & $\mathrm{s}$ \\
\hline 15 & 21.8 & 1.05 & $3 \mathrm{H}$ & $s$ \\
\hline $1^{\prime}$ & 72.7 & 4.55 & $2 \mathrm{H}$ & $\mathrm{m}$ \\
\hline $2^{\prime}$ & 55.4 & & & \\
\hline $3^{\prime}$ & 139.6 & & & \\
\hline $4^{\prime}$ & 202.3 & & & \\
\hline $5^{\prime}$ & 51.0 & & & \\
\hline $6^{\prime}$ & 143.4 & 6.78 & $1 \mathrm{H}$ & brs \\
\hline $7^{\prime}$ & 155.7 & & & \\
\hline $8^{\prime}$ & 166.4 & & & \\
\hline \multirow[t]{2}{*}{$9^{\prime}$} & 102.9 & 4.73 & $1 \mathrm{H}$ & $\mathrm{d}(\mathrm{J}=1.2 \mathrm{~Hz})$ \\
\hline & & 4.66 & $1 \mathrm{H}$ & $\mathrm{d}(J=1.2 \mathrm{~Hz})$ \\
\hline $10^{\prime}$ & 20.6 & 1.35 & $3 \mathrm{H}$ & $\mathrm{s}$ \\
\hline
\end{tabular}

${ }^{1} \mathrm{H}$ NMR: $500 \mathrm{MHz},{ }^{13} \mathrm{C}$ NMR: $125 \mathrm{MHz}$ (in $\mathrm{CDCl}_{3}$ ) 


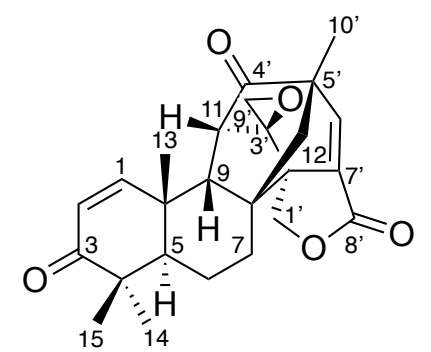

Table S8. NMR data for emervaridone C (5).

\begin{tabular}{|c|c|c|c|c|}
\hline \multirow[b]{2}{*}{ position } & \multirow{2}{*}{$\begin{array}{c}{ }^{13} \mathrm{C} \\
\delta(\mathrm{ppm})\end{array}$} & \multicolumn{3}{|c|}{${ }^{1} \mathrm{H}$} \\
\hline & & $\delta(p p m)$ & intensitiy & multiplicity \\
\hline 1 & 152.8 & 6.50 & $1 \mathrm{H}$ & $\mathrm{d}(\mathrm{J}=10.3 \mathrm{~Hz})$ \\
\hline 2 & 125.6 & 5.87 & $1 \mathrm{H}$ & $\mathrm{d}(J=10.3 \mathrm{~Hz})$ \\
\hline 3 & 203.4 & & & \\
\hline 4 & 44.6 & & & \\
\hline 5 & 39.3 & 2.27 & $1 \mathrm{H}$ & $\mathrm{m}$ \\
\hline \multirow[t]{2}{*}{6} & 17.0 & 1.85 & $1 \mathrm{H}$ & $\mathrm{m}$ \\
\hline & & 1.65 & $1 \mathrm{H}$ & $\mathrm{m}$ \\
\hline \multirow[t]{2}{*}{7} & 26.3 & 2.13 & $1 \mathrm{H}$ & $\mathrm{m}$ \\
\hline & & 1.99 & $1 \mathrm{H}$ & $\mathrm{m}$ \\
\hline 8 & 47.9 & & & \\
\hline 9 & 63.2 & 2.05 & $1 \mathrm{H}$ & $\mathrm{m}$ \\
\hline 10 & 37.5 & & & \\
\hline 11 & 66.9 & 2.98 & $1 \mathrm{H}$ & s \\
\hline \multirow[t]{2}{*}{12} & 56.4 & 1.79 & $1 \mathrm{H}$ & $\mathrm{m}$ \\
\hline & & 1.65 & $1 \mathrm{H}$ & $\mathrm{m}$ \\
\hline 13 & 26.8 & 1.33 & $3 \mathrm{H}$ & $\mathrm{s}$ \\
\hline 14 & 24.5 & 1.20 & $3 \mathrm{H}$ & $\mathrm{s}$ \\
\hline 15 & 21.8 & 1.08 & $3 \mathrm{H}$ & $\mathrm{s}$ \\
\hline \multirow[t]{2}{*}{$1^{\prime}$} & 68.0 & 4.45 & $1 \mathrm{H}$ & $\mathrm{d}(J=9.7 \mathrm{~Hz})$ \\
\hline & & 4.36 & $1 \mathrm{H}$ & $\mathrm{d}(J=9.7 \mathrm{~Hz})$ \\
\hline $2^{\prime}$ & 53.8 & & & \\
\hline $3^{\prime}$ & 72.5 & & & \\
\hline $4^{\prime}$ & 202.5 & & & \\
\hline $5^{\prime}$ & 51.4 & & & \\
\hline $6^{\prime}$ & 143.9 & 6.85 & $1 \mathrm{H}$ & brs \\
\hline $7^{\prime}$ & 138.6 & & & \\
\hline $8^{\prime}$ & 167.0 & & & \\
\hline \multirow[t]{2}{*}{$9^{\prime}$} & 47.4 & 2.72 & $1 \mathrm{H}$ & $\mathrm{d}(J=3.3 \mathrm{~Hz})$ \\
\hline & & 2.45 & $1 \mathrm{H}$ & $\mathrm{d}(\mathrm{J}=3.3 \mathrm{~Hz})$ \\
\hline $10^{\prime}$ & 20.6 & 1.41 & $3 \mathrm{H}$ & $\mathrm{s}$ \\
\hline
\end{tabular}

${ }^{1} \mathrm{H}$ NMR: $500 \mathrm{MHz},{ }^{13} \mathrm{C}$ NMR: $125 \mathrm{MHz}$ (in $\mathrm{CDCl}_{3}$ ) 


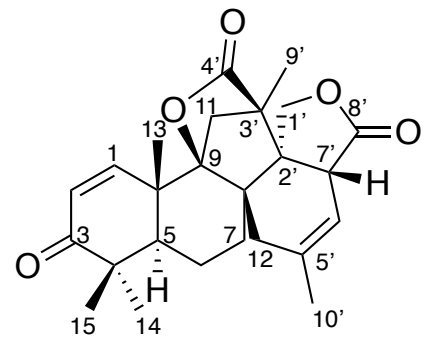

Table S9. NMR data for emeridone A $\left(\mathbf{6}^{\prime}\right)$.

\begin{tabular}{|c|c|c|c|c|}
\hline \multirow[b]{2}{*}{ position } & \multirow{2}{*}{$\begin{array}{c}{ }^{13} \mathrm{C} \\
\delta(\mathrm{ppm})\end{array}$} & \multicolumn{3}{|c|}{${ }^{1} \mathrm{H}$} \\
\hline & & $\delta(p p m)$ & intensitiy & multiplicity \\
\hline 1 & 153.7 & 7.05 & $1 \mathrm{H}$ & $\mathrm{d}(J=10.2 \mathrm{~Hz})$ \\
\hline 2 & 126.3 & 5.94 & $1 \mathrm{H}$ & $\mathrm{d}(\mathrm{J}=10.2 \mathrm{~Hz})$ \\
\hline 3 & 203.2 & & & \\
\hline 4 & 44.4 & & & \\
\hline 5 & 47.2 & 1.84 & $1 \mathrm{H}$ & $\mathrm{m}$ \\
\hline \multirow[t]{2}{*}{6} & 19.3 & 1.84 & $1 \mathrm{H}$ & $\mathrm{m}$ \\
\hline & & 1.68 & $1 \mathrm{H}$ & $\mathrm{m}$ \\
\hline \multirow[t]{2}{*}{7} & 33.9 & 1.64 & $1 \mathrm{H}$ & $\mathrm{m}$ \\
\hline & & 1.18 & $1 \mathrm{H}$ & $\mathrm{m}$ \\
\hline 8 & 50.3 & & & \\
\hline 9 & 92.3 & & & \\
\hline 10 & 40.9 & & & \\
\hline \multirow[t]{2}{*}{11} & 43.4 & 2.34 & $1 \mathrm{H}$ & $\mathrm{m}$ \\
\hline & & 1.87 & $1 \mathrm{H}$ & $\mathrm{m}$ \\
\hline \multirow[t]{2}{*}{12} & 35.4 & 2.34 & $1 \mathrm{H}$ & $\mathrm{m}$ \\
\hline & & 2.17 & $1 \mathrm{H}$ & $\mathrm{d}(J=15.1 \mathrm{~Hz})$ \\
\hline 13 & 19.4 & 1.44 & $3 \mathrm{H}$ & $\mathrm{s}$ \\
\hline 14 & 21.8 & 1.20 & $3 \mathrm{H}$ & s \\
\hline 15 & 27.4 & 1.14 & $3 \mathrm{H}$ & $\mathrm{s}$ \\
\hline \multirow[t]{2}{*}{$1^{\prime}$} & 70.9 & 4.11 & $1 \mathrm{H}$ & $\mathrm{d}(J=9.6 \mathrm{~Hz})$ \\
\hline & & 4.07 & $1 \mathrm{H}$ & $\mathrm{d}(J=9.6 \mathrm{~Hz})$ \\
\hline $2^{\prime}$ & 54.1 & & & \\
\hline $3^{\prime}$ & 54.4 & & & \\
\hline $4^{\prime}$ & 176.1 & & & \\
\hline $5^{\prime}$ & 139.3 & & & \\
\hline $6^{\prime}$ & 116.0 & 5.41 & $1 \mathrm{H}$ & brs \\
\hline $7^{\prime}$ & 44.2 & 2.88 & $1 \mathrm{H}$ & $\mathrm{m}$ \\
\hline $8^{\prime}$ & 176.6 & & & \\
\hline $9^{\prime}$ & 11.2 & 1.24 & $3 \mathrm{H}$ & s \\
\hline $10^{\prime}$ & 24.8 & 1.84 & $3 \mathrm{H}$ & s \\
\hline
\end{tabular}

${ }^{1} \mathrm{H}$ NMR: $500 \mathrm{MHz},{ }^{13} \mathrm{C}$ NMR: $125 \mathrm{MHz}$ (in $\mathrm{CDCl}_{3}$ ) 


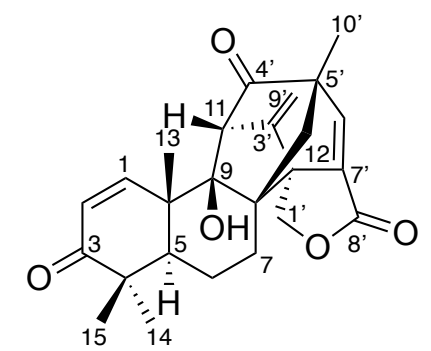

Table S10. NMR data for emervaridione (7).

\begin{tabular}{|c|c|c|c|c|}
\hline \multirow[b]{2}{*}{ position } & \multirow{2}{*}{$\begin{array}{c}{ }^{13} \mathrm{C} \\
\delta(\mathrm{ppm})\end{array}$} & \multicolumn{3}{|c|}{${ }^{1} \mathrm{H}$} \\
\hline & & $\delta(p p m)$ & intensitiy & multiplicity \\
\hline 1 & 149.8 & 6.75 & $1 \mathrm{H}$ & $\mathrm{d}(J=10.2 \mathrm{~Hz})$ \\
\hline 2 & 126.7 & 5.95 & $1 \mathrm{H}$ & $\mathrm{d}(\mathrm{J}=10.2 \mathrm{~Hz})$ \\
\hline 3 & 202.7 & & & \\
\hline 4 & 44.6 & & & \\
\hline 5 & 41.2 & 2.13 & $1 \mathrm{H}$ & $\mathrm{dd}(J=13.6,6.0 \mathrm{~Hz})$ \\
\hline \multirow[t]{2}{*}{6} & 25.2 & 2.05 & $1 \mathrm{H}$ & $\mathrm{m}$ \\
\hline & & 1.80 & $1 \mathrm{H}$ & $\mathrm{m}$ \\
\hline \multirow[t]{2}{*}{7} & 17.1 & 1.80 & $1 \mathrm{H}$ & $\mathrm{m}$ \\
\hline & & 1.55 & $1 \mathrm{H}$ & $\mathrm{m}$ \\
\hline 8 & 51.4 & & & \\
\hline 9 & 82.4 & & & \\
\hline 10 & 43.7 & & & \\
\hline 11 & 73.3 & 3.68 & $1 \mathrm{H}$ & $\mathrm{s}$ \\
\hline \multirow[t]{2}{*}{12} & 48.1 & 2.35 & $1 \mathrm{H}$ & $\mathrm{d}(\mathrm{J}=12.0 \mathrm{~Hz})$ \\
\hline & & 1.38 & $1 \mathrm{H}$ & $\mathrm{m}$ \\
\hline 13 & 17.6 & 1.27 & $3 \mathrm{H}$ & s \\
\hline 14 & 25.2 & 1.16 & $3 \mathrm{H}$ & s \\
\hline 15 & 22.4 & 1.11 & $3 \mathrm{H}$ & $\mathrm{s}$ \\
\hline \multirow[t]{2}{*}{$1^{\prime}$} & 72.5 & 4.61 & $1 \mathrm{H}$ & $\mathrm{d}(J=9.7 \mathrm{~Hz})$ \\
\hline & & 4.50 & $1 \mathrm{H}$ & $\mathrm{d}(J=9.7 \mathrm{~Hz})$ \\
\hline $2^{\prime}$ & 57.7 & & & \\
\hline $3^{\prime}$ & 138.4 & & & \\
\hline $4^{\prime}$ & 201.9 & & & \\
\hline $5^{\prime}$ & 50.3 & & & \\
\hline $6^{\prime}$ & 144.7 & 6.87 & $1 \mathrm{H}$ & brs \\
\hline $7^{\prime}$ & 152.7 & & & \\
\hline $8^{\prime}$ & 166.3 & & & \\
\hline \multirow[t]{2}{*}{$9^{\prime}$} & 103.3 & 4.77 & $1 \mathrm{H}$ & $\mathrm{d}(\mathrm{J}=1.3 \mathrm{~Hz})$ \\
\hline & & 4.69 & $1 \mathrm{H}$ & $\mathrm{d}(J=1.3 \mathrm{~Hz})$ \\
\hline $10^{\prime}$ & 19.8 & 1.35 & $3 \mathrm{H}$ & $\mathrm{s}$ \\
\hline
\end{tabular}

${ }^{1} \mathrm{H}$ NMR: $500 \mathrm{MHz},{ }^{13} \mathrm{C}$ NMR: $125 \mathrm{MHz}$ (in $\mathrm{CDCl}_{3}$ ) 


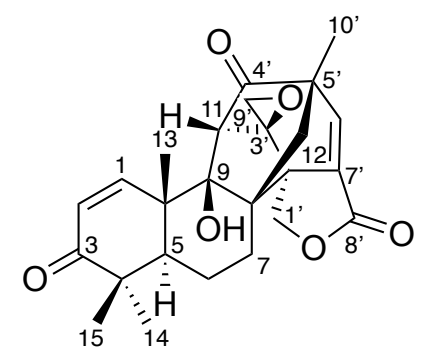

Table S11. NMR data for emeridone F (8).

\begin{tabular}{|c|c|c|c|c|}
\hline \multirow[b]{2}{*}{ position } & \multirow{2}{*}{$\begin{array}{c}{ }^{13} \mathrm{C} \\
\delta(\mathrm{ppm})\end{array}$} & \multicolumn{3}{|c|}{${ }^{1} \mathrm{H}$} \\
\hline & & $\delta(p p m)$ & intensitiy & multiplicity \\
\hline 1 & 155.6 & 6.94 & $1 \mathrm{H}$ & $\mathrm{d}(J=10.3 \mathrm{~Hz})$ \\
\hline 2 & 126.2 & 5.85 & $1 \mathrm{H}$ & $\mathrm{d}(J=10.3 \mathrm{~Hz})$ \\
\hline 3 & 206.3 & & & \\
\hline 4 & 45.8 & & & \\
\hline 5 & 40.5 & 2.40 & $1 \mathrm{H}$ & $\mathrm{dd}(J=13.8,5.9 \mathrm{~Hz})$ \\
\hline \multirow[t]{2}{*}{6} & 17.9 & 1.83 & $1 \mathrm{H}$ & $\mathrm{m}$ \\
\hline & & 1.68 & $1 \mathrm{H}$ & $\mathrm{m}$ \\
\hline \multirow[t]{2}{*}{7} & 25.7 & 2.09 & $1 \mathrm{H}$ & $\mathrm{m}$ \\
\hline & & 1.93 & $1 \mathrm{H}$ & $\mathrm{m}$ \\
\hline 8 & 52.3 & & & \\
\hline 9 & 85.5 & & & \\
\hline 10 & 45.2 & & & \\
\hline 11 & 73.4 & 2.93 & $1 \mathrm{H}$ & s \\
\hline \multirow[t]{2}{*}{12} & 49.4 & 2.46 & $1 \mathrm{H}$ & $\mathrm{m}$ \\
\hline & & 1.35 & $1 \mathrm{H}$ & $\mathrm{d}(\mathrm{J}=11.8 \mathrm{~Hz})$ \\
\hline 13 & 19.0 & 1.30 & $3 \mathrm{H}$ & $\mathrm{s}$ \\
\hline 14 & 23.0 & 1.23 & $3 \mathrm{H}$ & s \\
\hline 15 & 25.4 & 1.16 & $3 \mathrm{H}$ & $\mathrm{s}$ \\
\hline \multirow[t]{2}{*}{$1^{\prime}$} & 69.7 & 4.55 & $1 \mathrm{H}$ & $\mathrm{d}(J=9.7 \mathrm{~Hz})$ \\
\hline & & 4.43 & $1 \mathrm{H}$ & $\mathrm{d}(J=9.7 \mathrm{~Hz})$ \\
\hline $2^{\prime}$ & 57.1 & & & \\
\hline $3^{\prime}$ & 70.4 & & & \\
\hline $4^{\prime}$ & 203.6 & & & \\
\hline $5^{\prime}$ & 51.8 & & & \\
\hline $6^{\prime}$ & 146.3 & 6.87 & $1 \mathrm{H}$ & brs \\
\hline $7^{\prime}$ & 139.6 & & & \\
\hline $8^{\prime}$ & 169.2 & & & \\
\hline \multirow[t]{2}{*}{$9^{\prime}$} & 48.4 & 2.75 & $1 \mathrm{H}$ & $\mathrm{d}(J=3.6 \mathrm{~Hz})$ \\
\hline & & 2.46 & $1 \mathrm{H}$ & $\mathrm{d}(J=3.6 \mathrm{~Hz})$ \\
\hline $10^{\prime}$ & 20.1 & 1.39 & $3 \mathrm{H}$ & $\mathrm{s}$ \\
\hline
\end{tabular}

${ }^{1} \mathrm{H}$ NMR: $900 \mathrm{MHz},{ }^{13} \mathrm{C}$ NMR: $225 \mathrm{MHz}$ (in $\mathrm{CD}_{3} \mathrm{OD}$ ) 
(A)

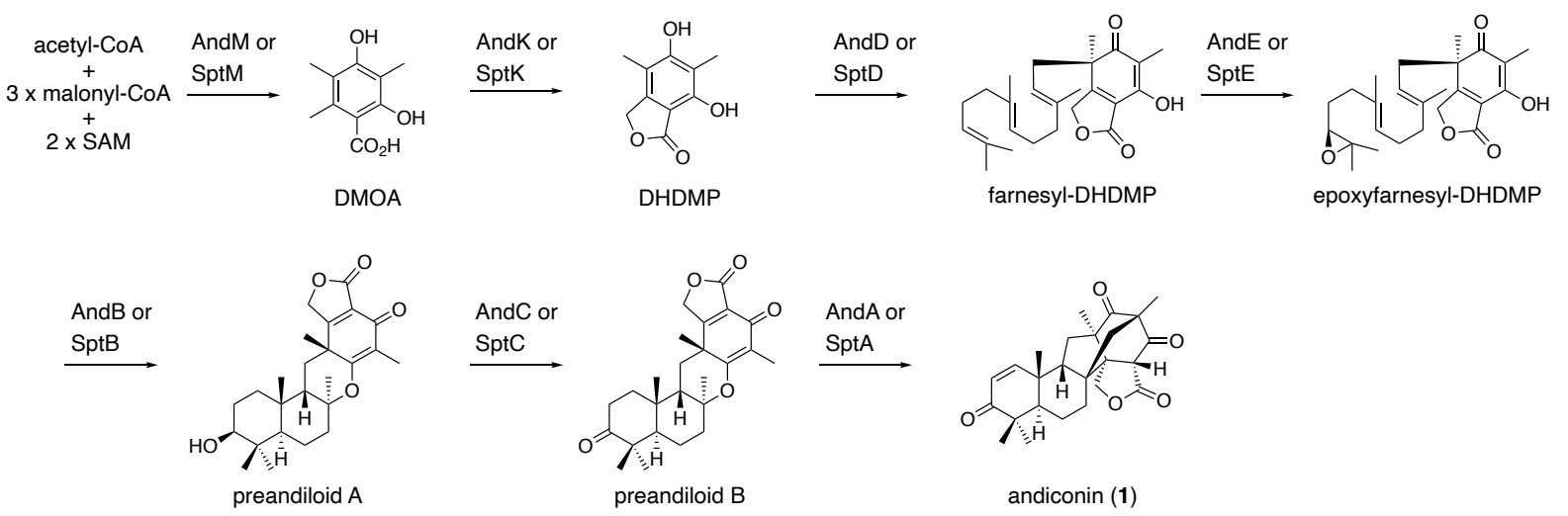

(B)
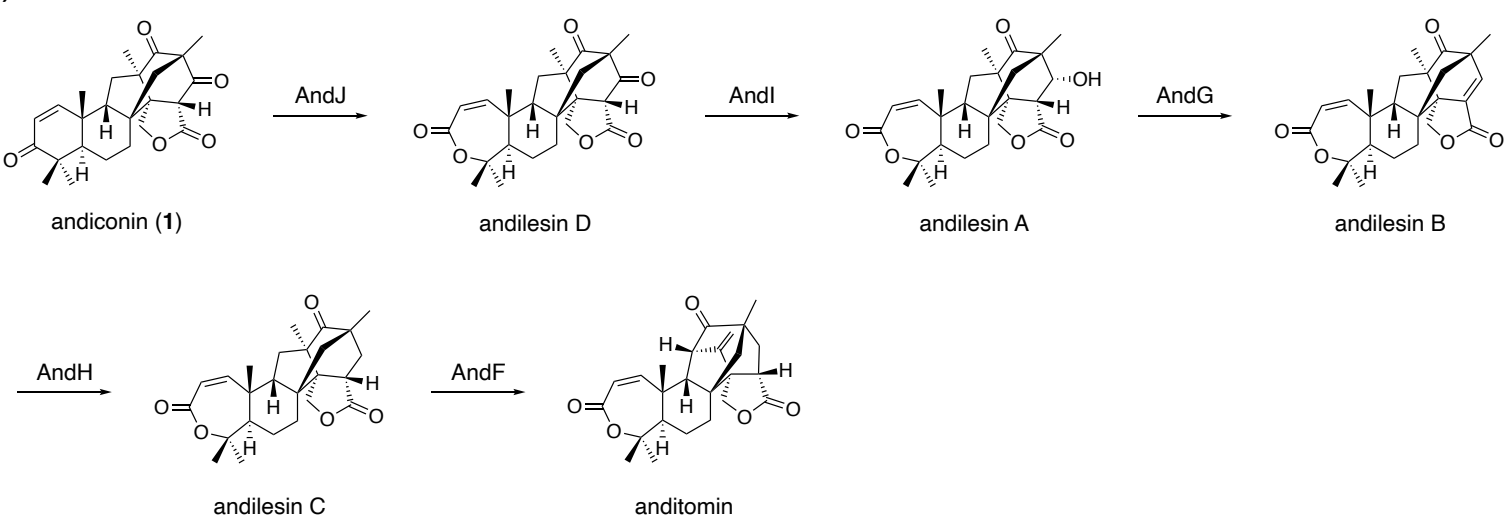

Figure S1. Biosynthetic pathway of (A) andiconin (1) and (B) anditomin.

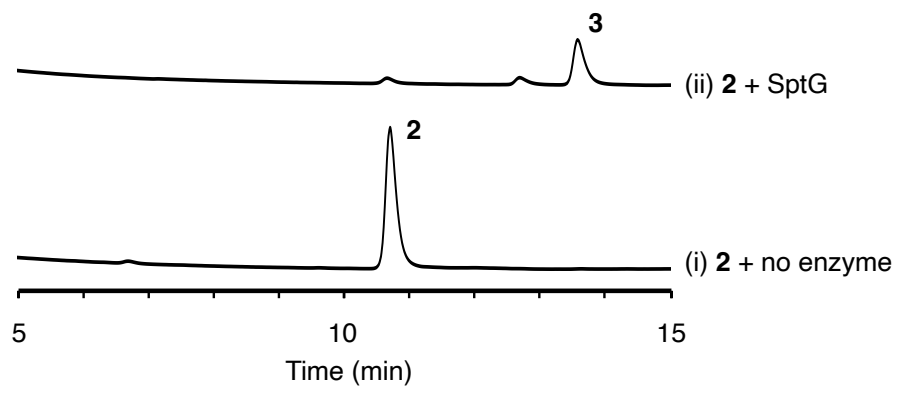

Figure S2. HPLC profiles of products from the reaction with $\mathbf{2}$ and SptG. The chromatograms were monitored at $254 \mathrm{~nm}$. 


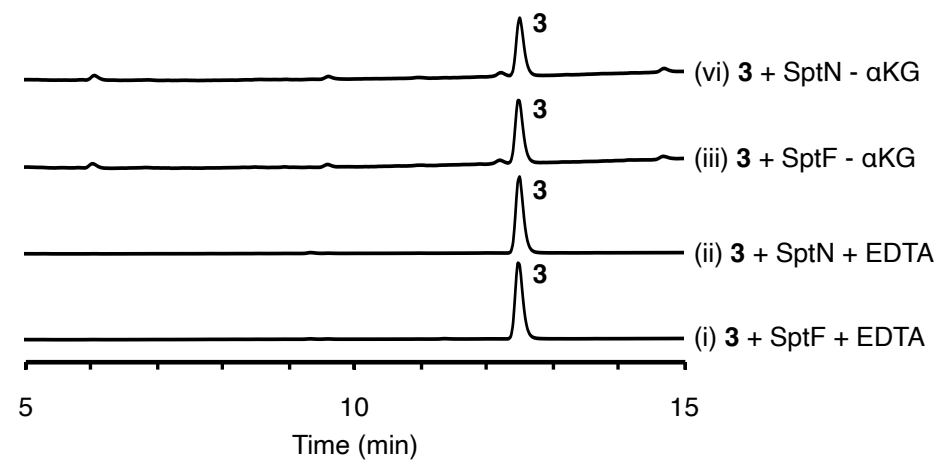

Figure S3. HPLC profiles of products the reaction with 2 and SptF or SptN in the presence of EDTA or in the absence of $\alpha \mathrm{KG}$. The chromatograms were monitored at $254 \mathrm{~nm}$.

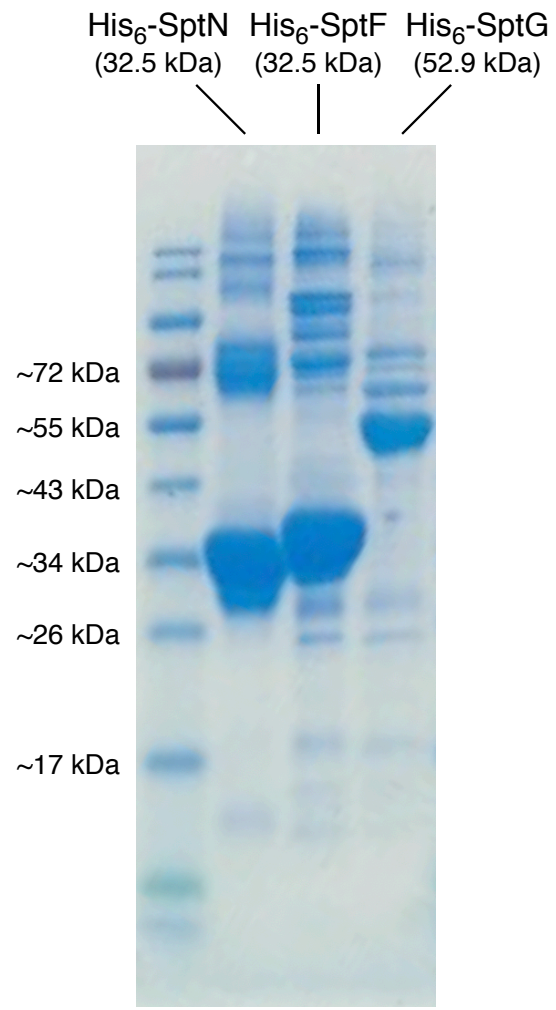

Figure S4. SDS-PAGE analysis of the purified proteins. 


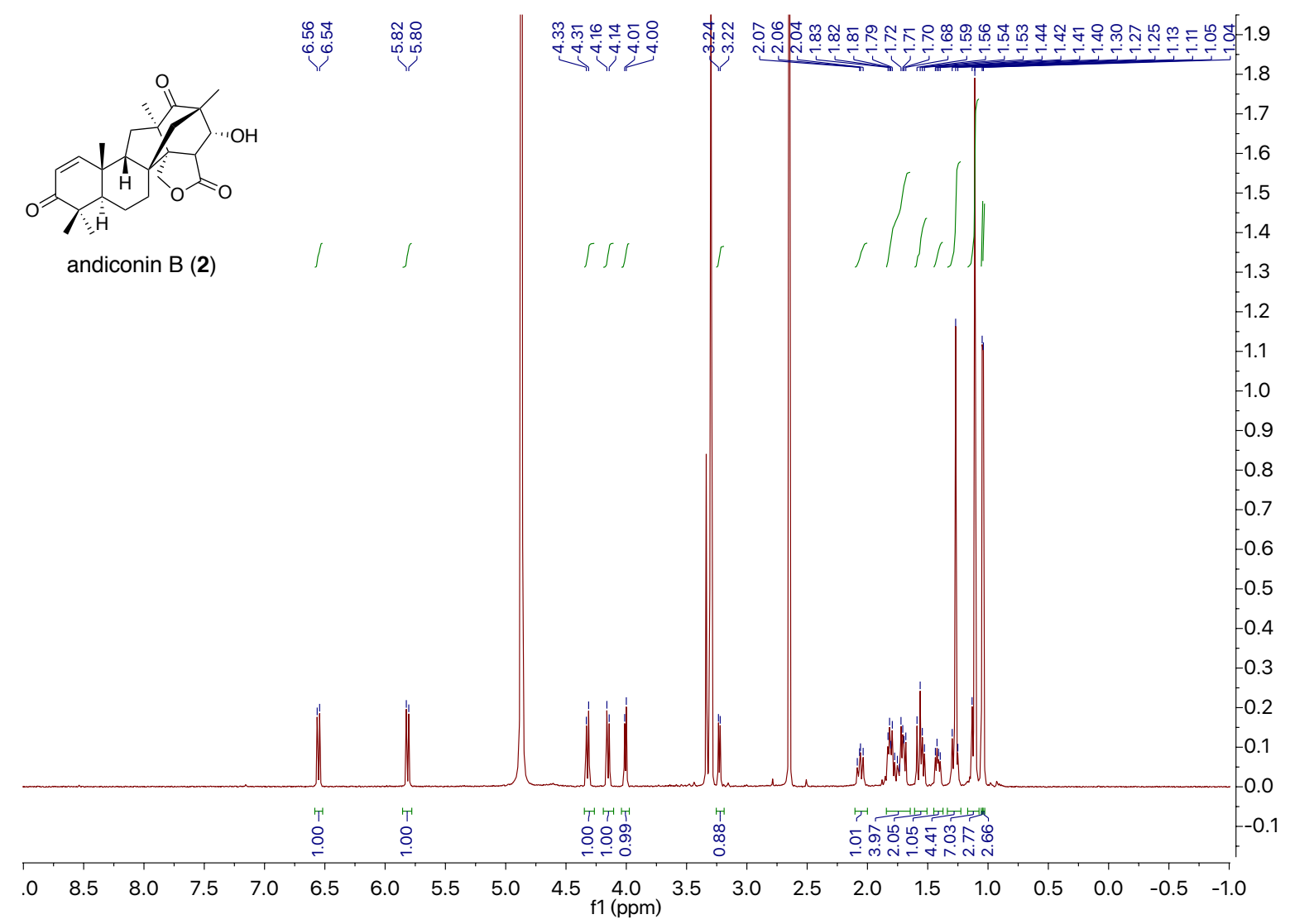

Figure S5. ${ }^{1} \mathrm{H}$ NMR spectrum of andiconin B (2) in $\mathrm{CD}_{3} \mathrm{OD}$ at $500 \mathrm{~Hz}$.

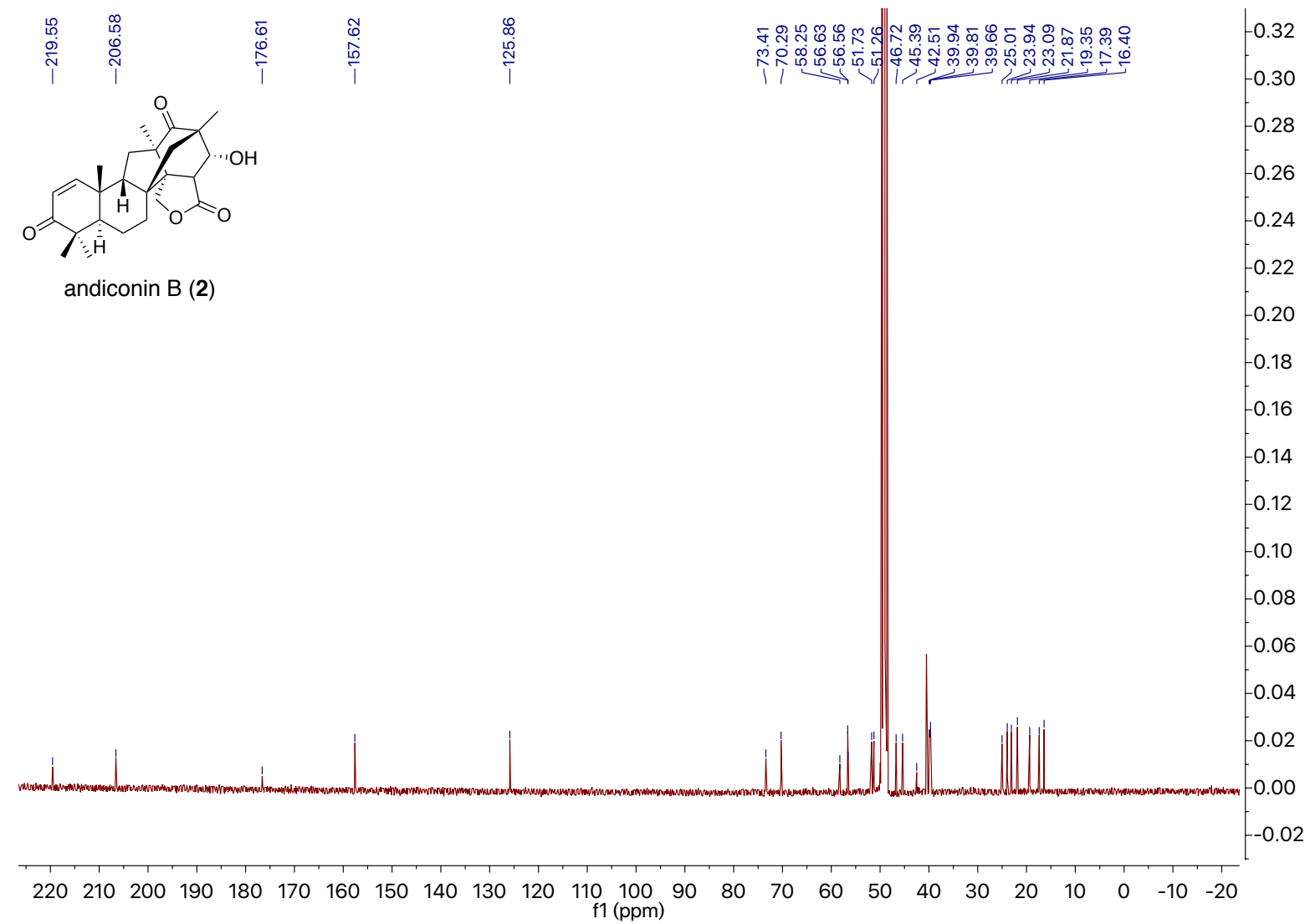

Figure S6. ${ }^{13} \mathrm{C}$ NMR spectrum of andiconin $\mathrm{B}(2)$ in $\mathrm{CD}_{3} \mathrm{OD}$ at $125 \mathrm{~Hz}$. 


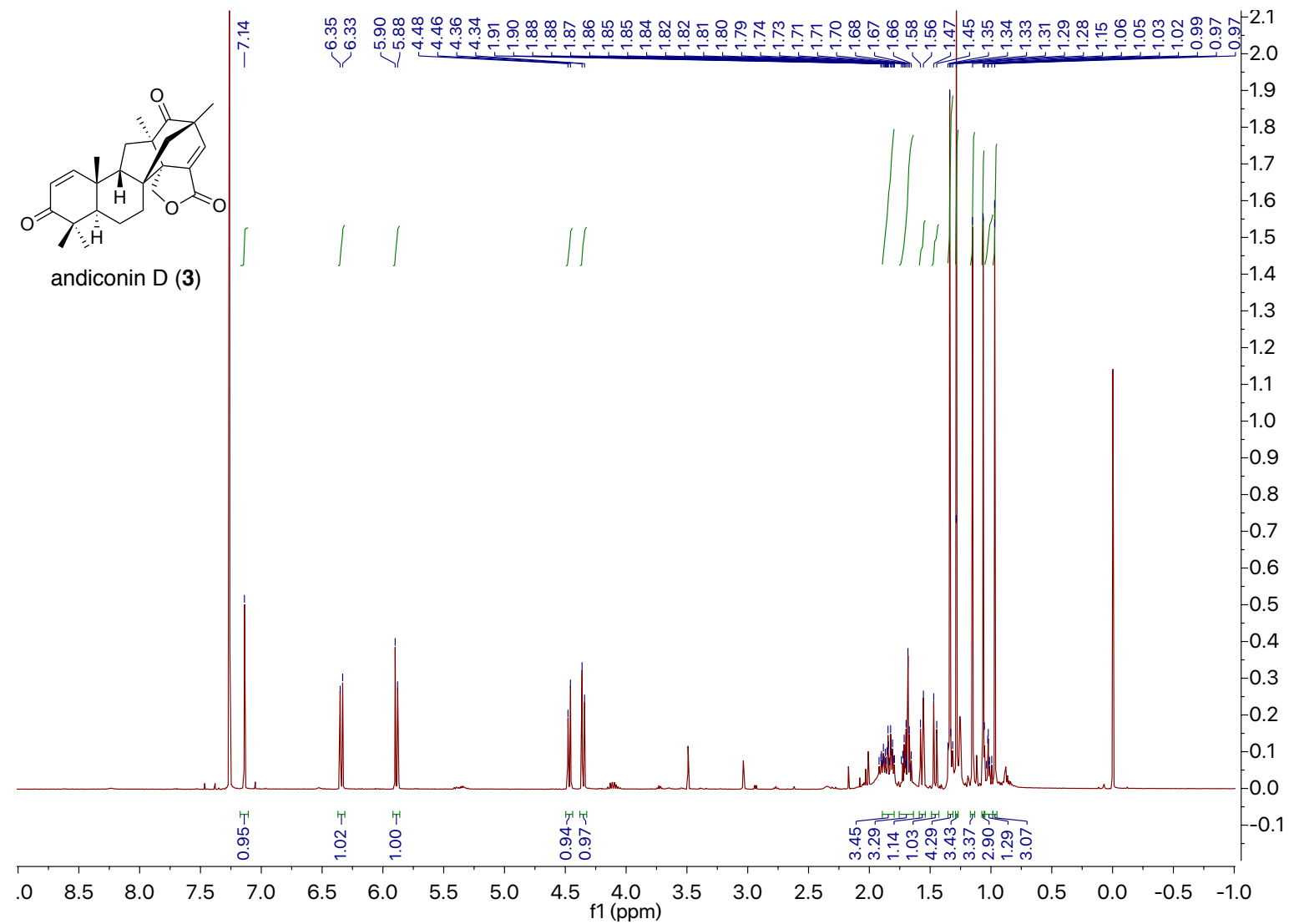

Figure S7. ${ }^{1} \mathrm{H}$ NMR spectrum of andiconin D (3) in $\mathrm{CDCl}_{3}$ at $500 \mathrm{~Hz}$.
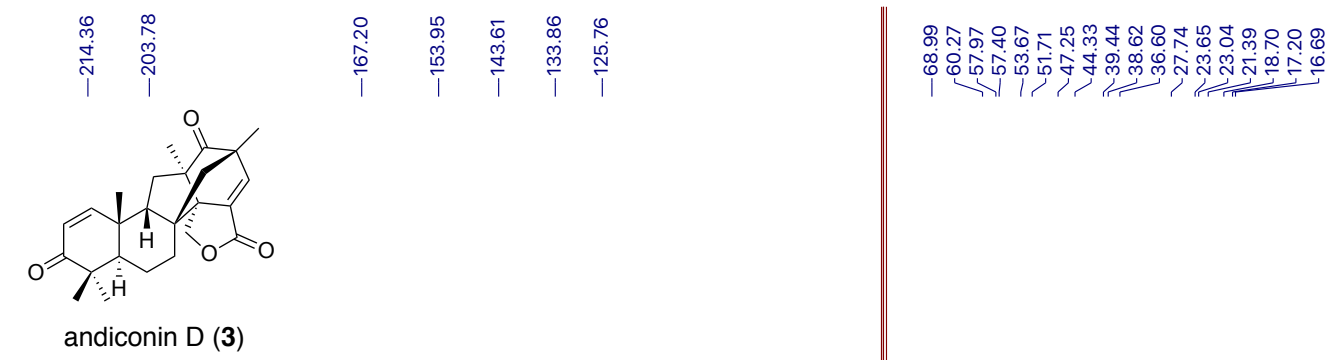

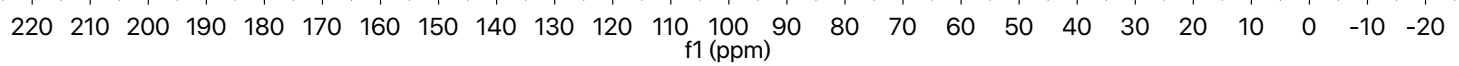

Figure S8. ${ }^{13} \mathrm{C}$ NMR spectrum of andiconin $\mathrm{D}(3)$ in $\mathrm{CDCl}_{3}$ at $125 \mathrm{~Hz}$. 


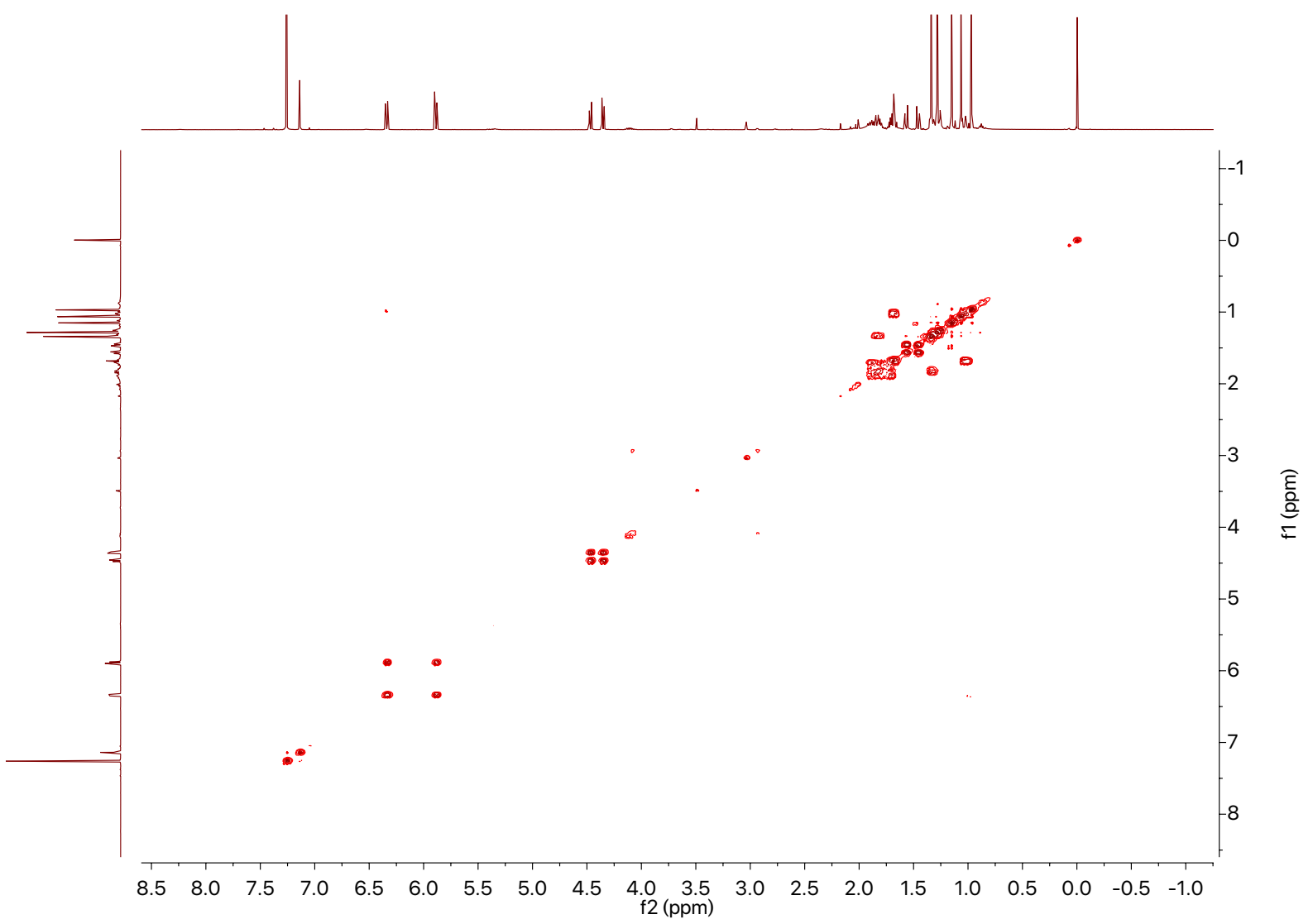

Figure S9. ${ }^{1} \mathrm{H}-{ }^{1} \mathrm{H}$ COSY spectrum of andiconin D (3).

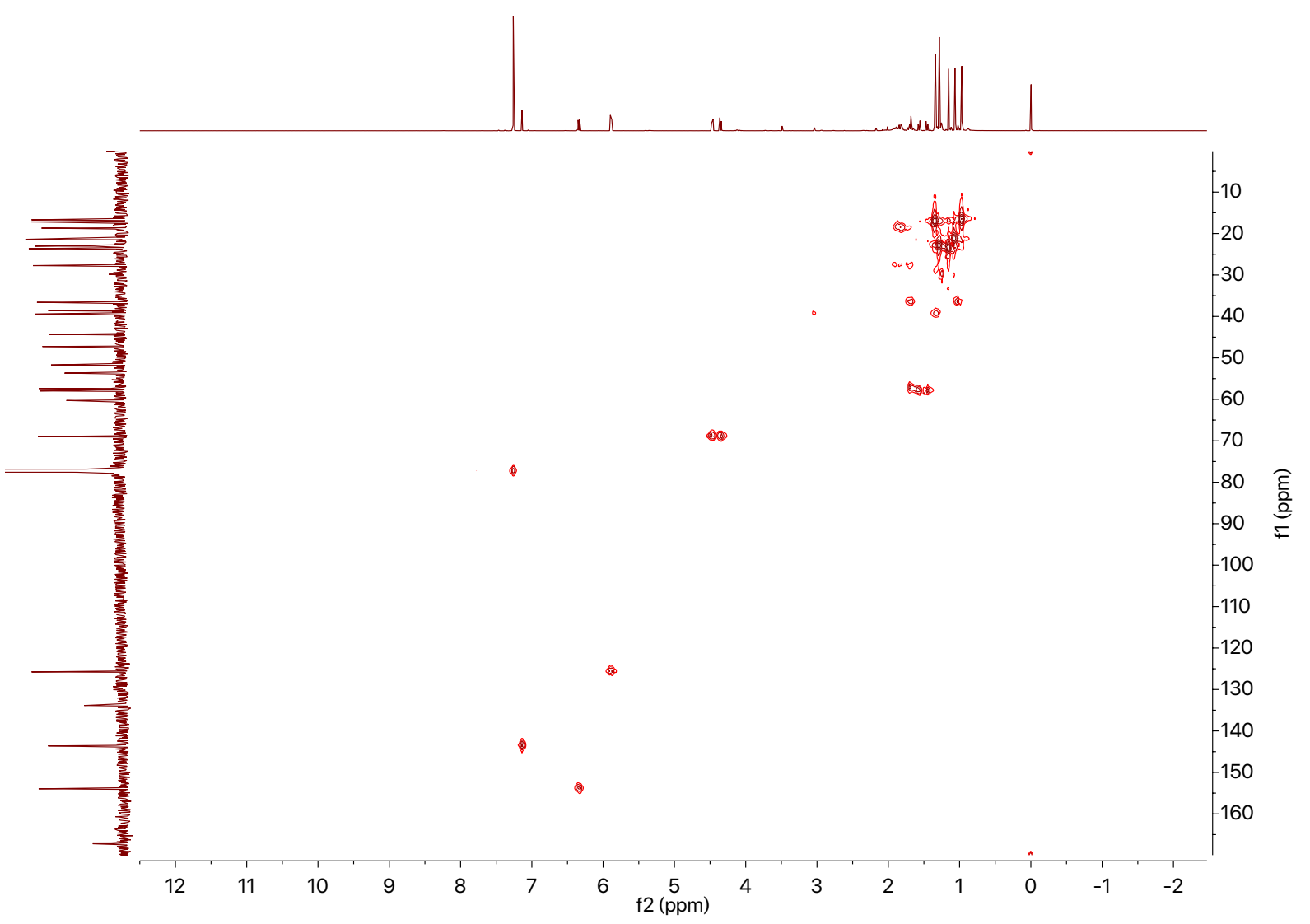

Figure S10. HMQC spectrum of andiconin D (3). 


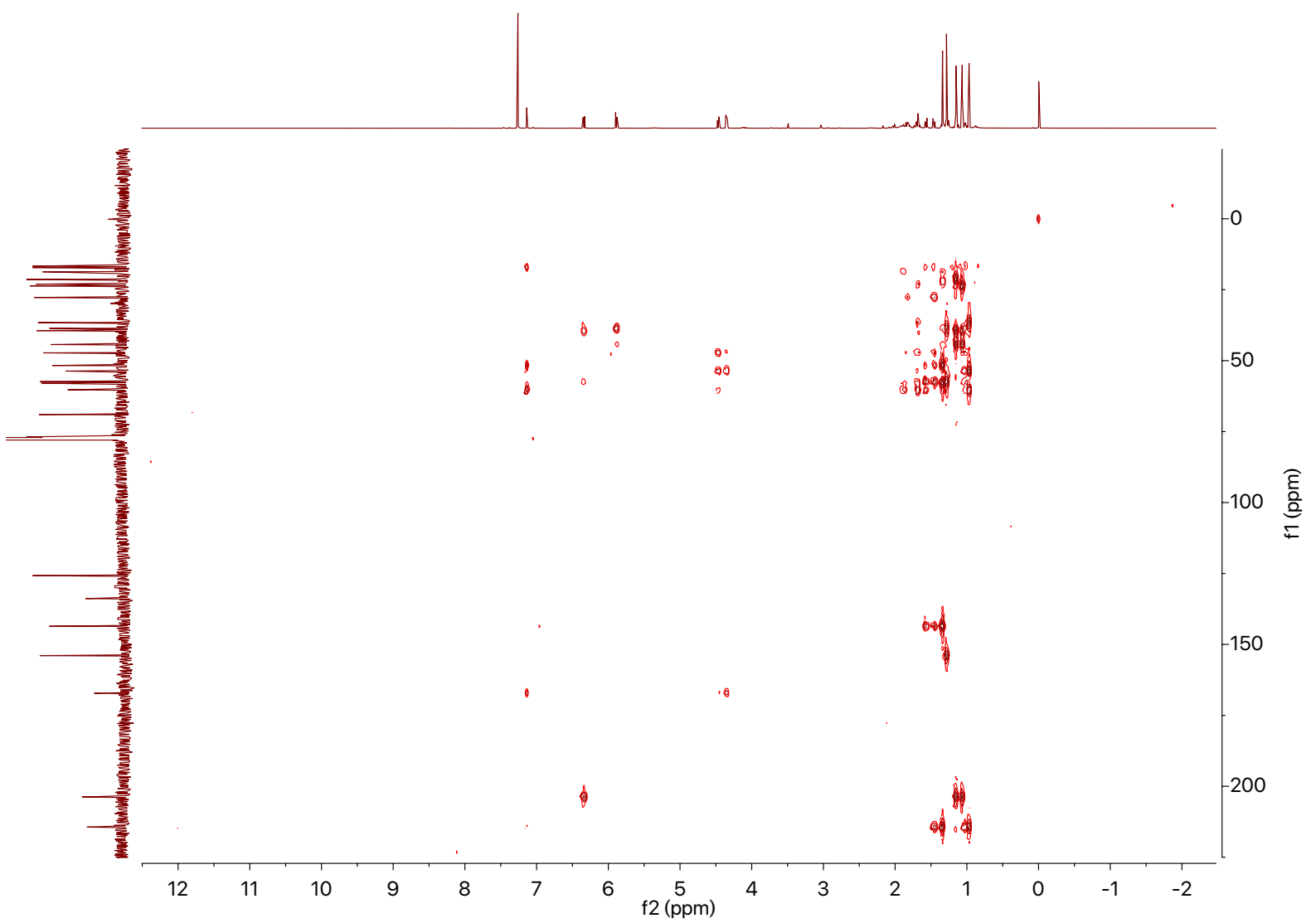

Figure S11. HMBC spectrum of andiconin D (3).

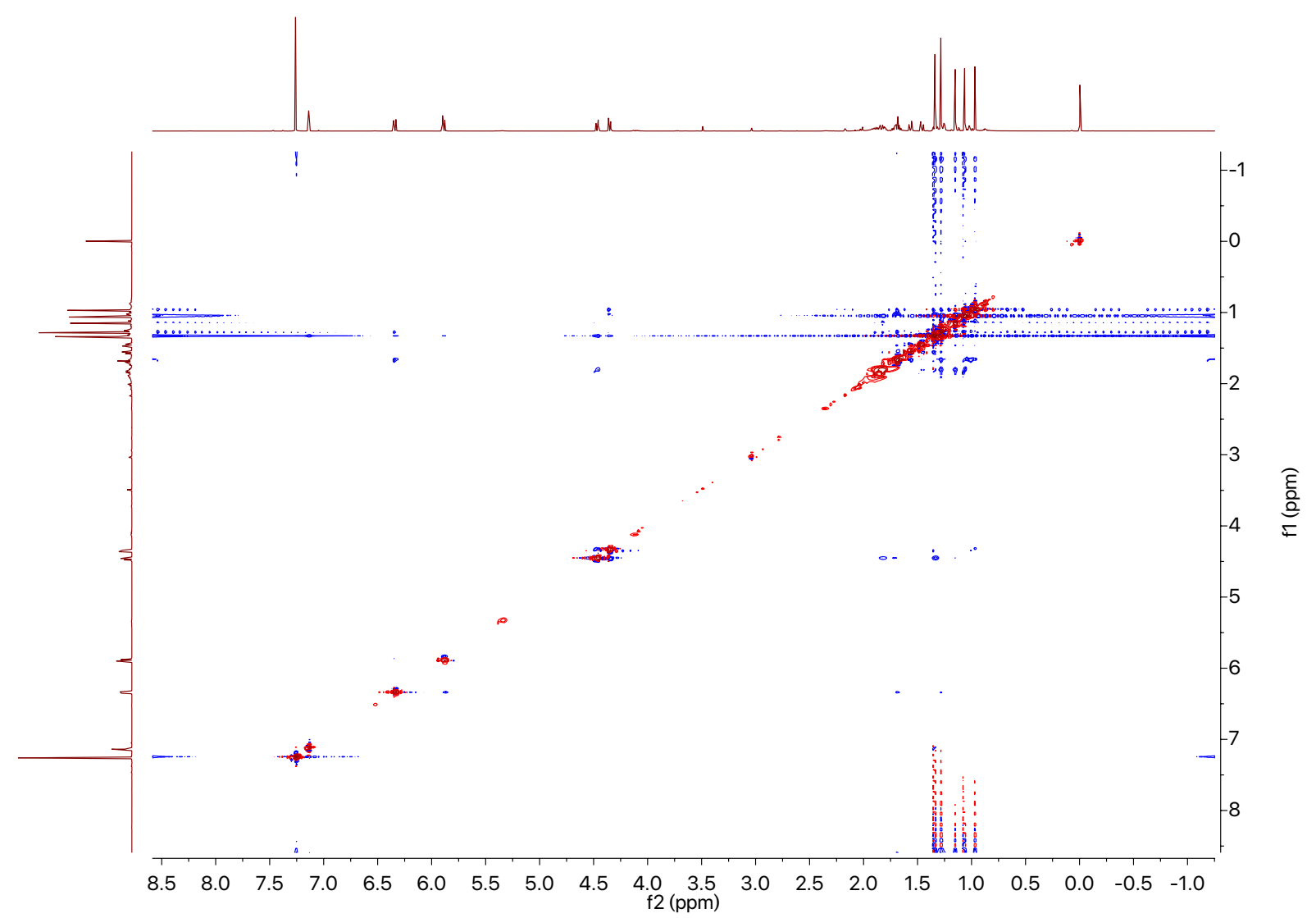

Figure S12. NOESY spectrum of andiconin D (3). 


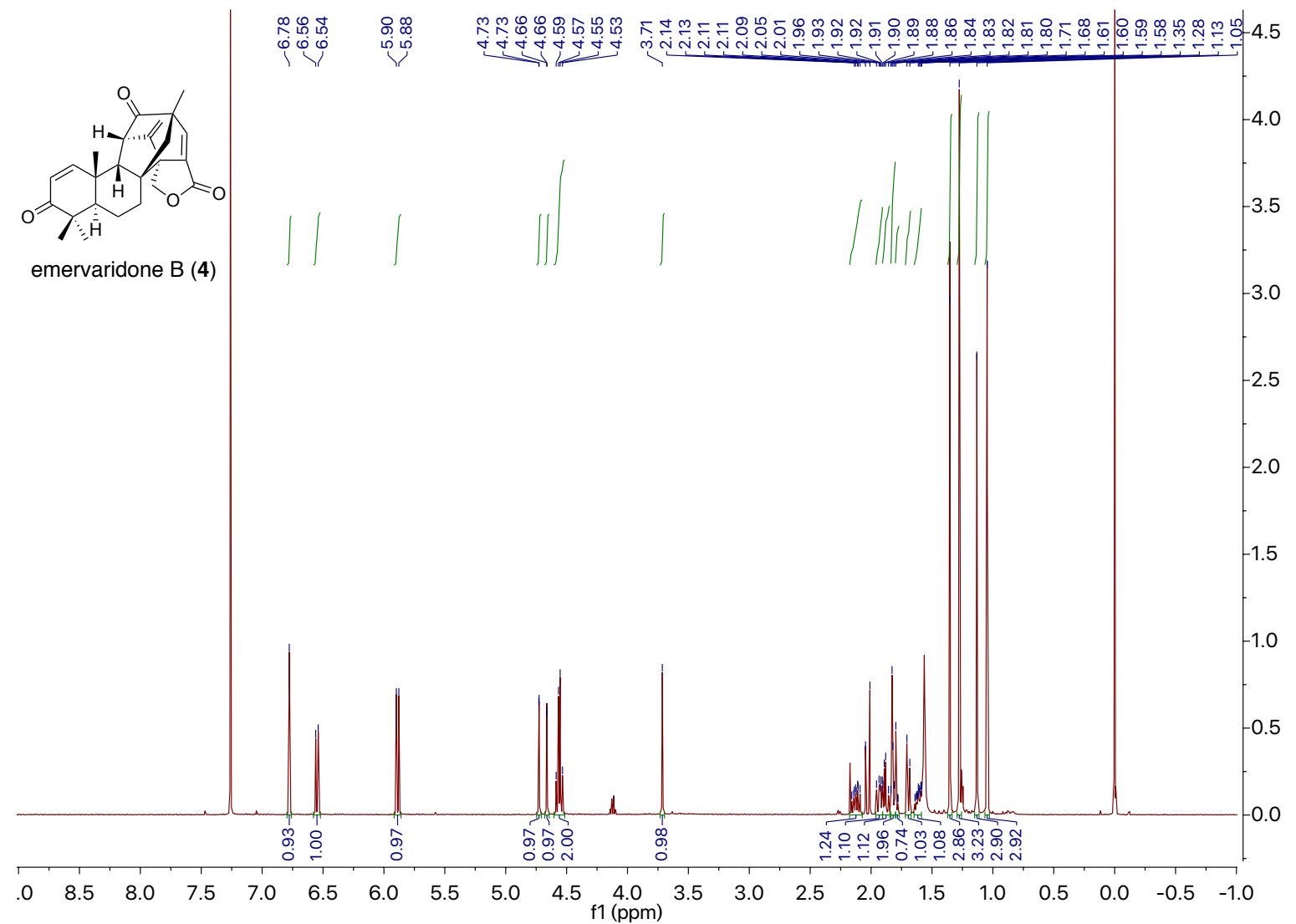

Figure S13. ${ }^{1} \mathrm{H}$ NMR spectrum of emervaridone B (4) in $\mathrm{CDCl}_{3}$ at $500 \mathrm{~Hz}$.
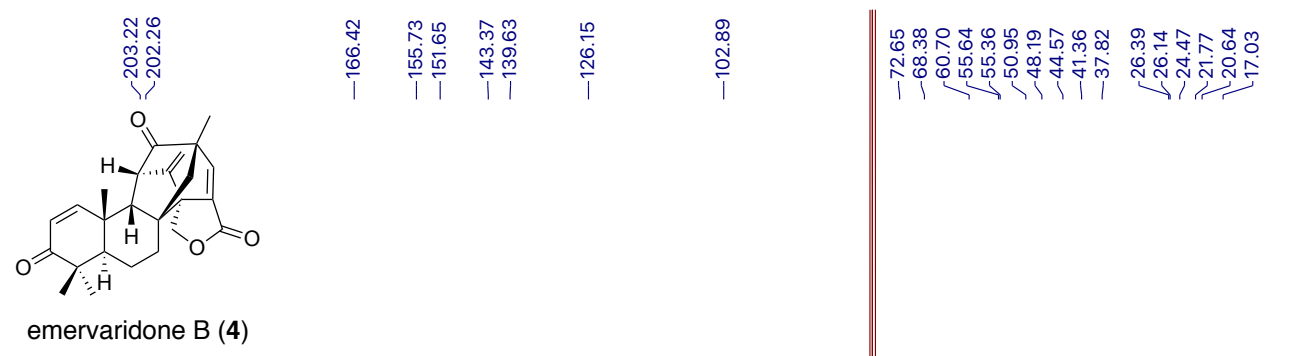

0.050
0.045
0.040
0.035
0.030
0.025
0.020
0.015
0.010
0.005
0.000

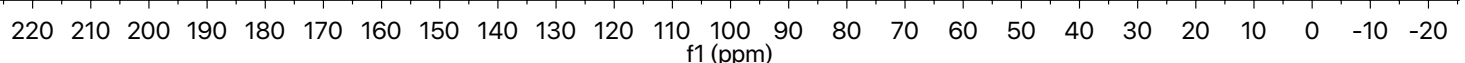

Figure S14. ${ }^{13} \mathrm{C}$ NMR spectrum of emervaridone $\mathrm{B}(4)$ in $\mathrm{CDCl}_{3}$ at $125 \mathrm{~Hz}$. 


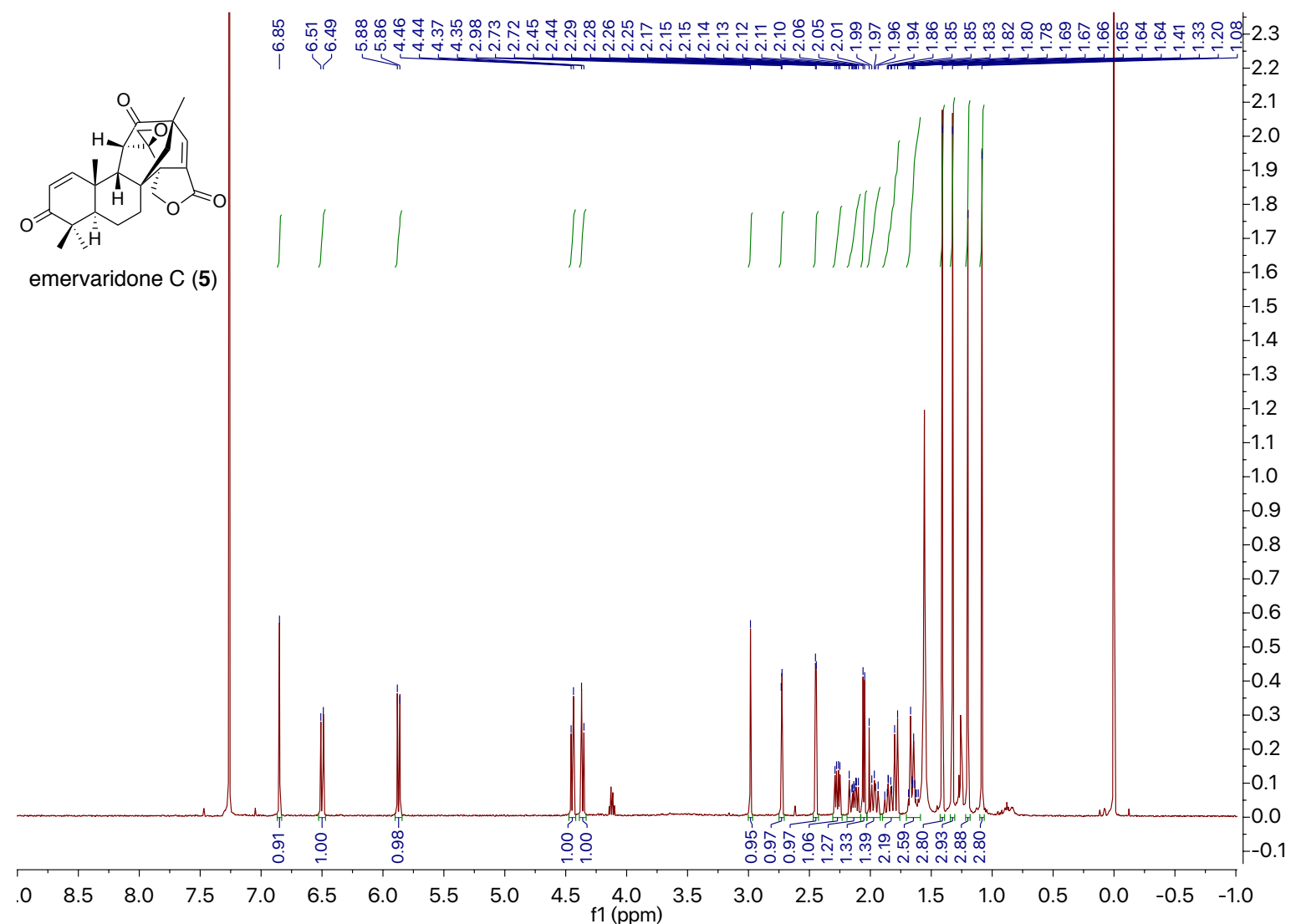

Figure S15. ${ }^{1} \mathrm{H}$ NMR spectrum of emervaridone $\mathrm{C}(\mathbf{5})$ in $\mathrm{CDCl}_{3}$ at $500 \mathrm{~Hz}$.
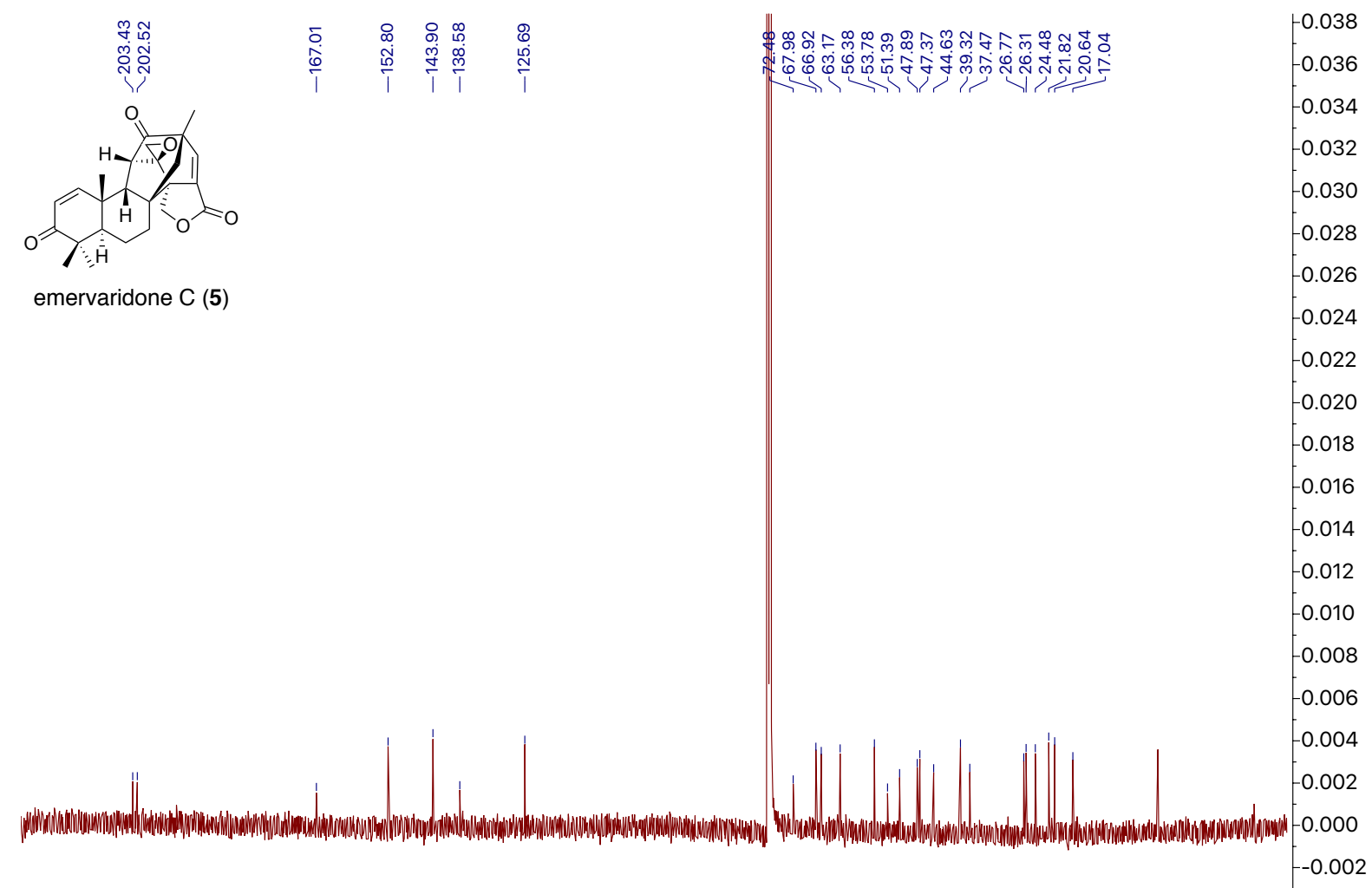

\begin{tabular}{lllllllllllllllllllllll}
\hline 220 & 210 & 200 & 190 & 180 & 170 & 160 & 150 & 140 & 130 & 120 & $110 \underset{\mathrm{f} 1(\mathrm{ppm})}{100} 90$ & 80 & 70 & 60 & 50 & 40 & 30 & 20 & 10 & 0 & -10 & -20
\end{tabular}

Figure S16. ${ }^{13} \mathrm{C}$ NMR spectrum of emervaridones $\mathrm{C}(\mathbf{5})$ in $\mathrm{CDCl}_{3}$ at $125 \mathrm{~Hz}$. 


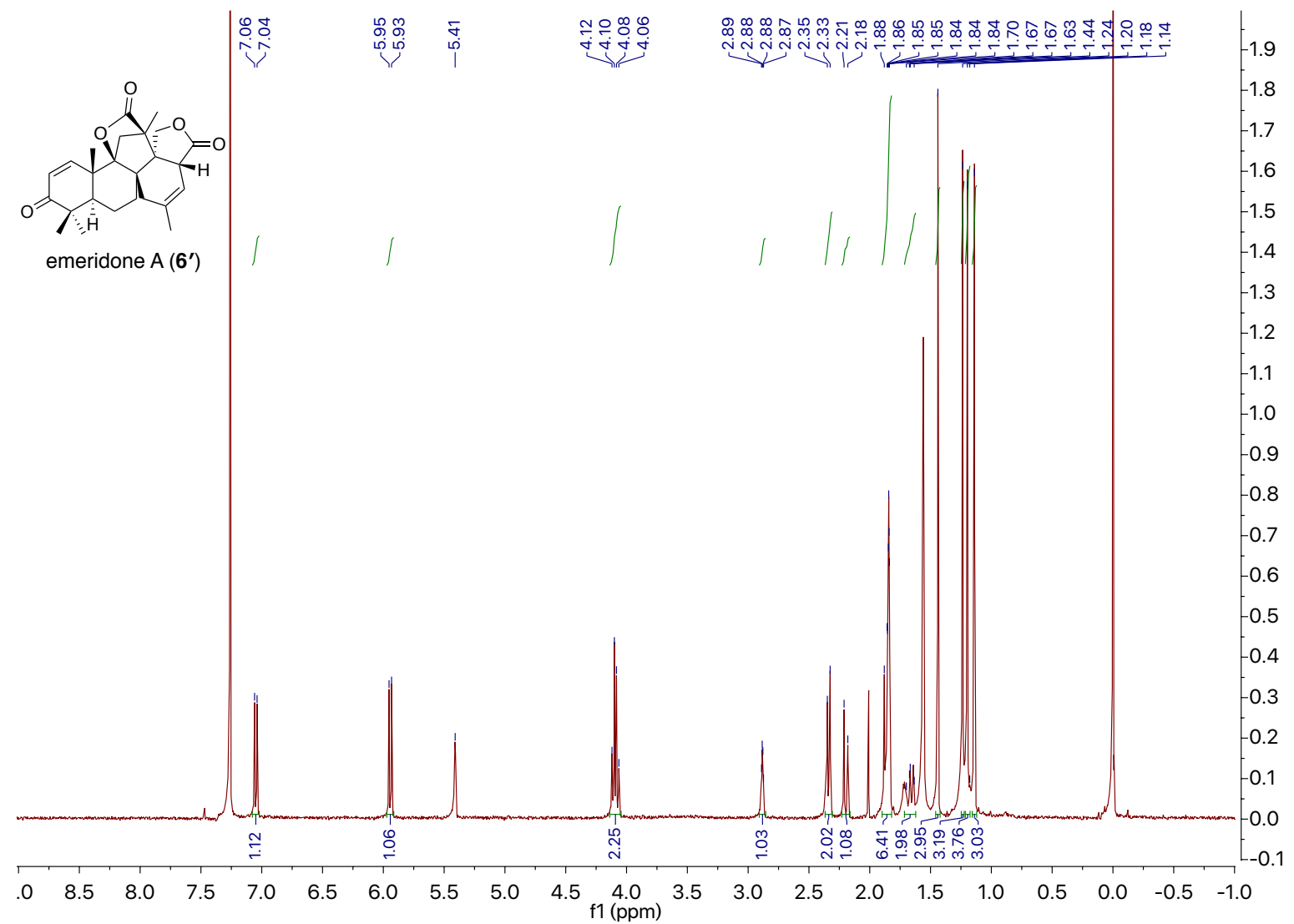

Figure S17. ${ }^{1} \mathrm{H}$ NMR spectrum of emeridone $\mathrm{A}\left(\mathbf{6}^{\prime}\right)$ in $\mathrm{CDCl}_{3}$ at $500 \mathrm{~Hz}$.

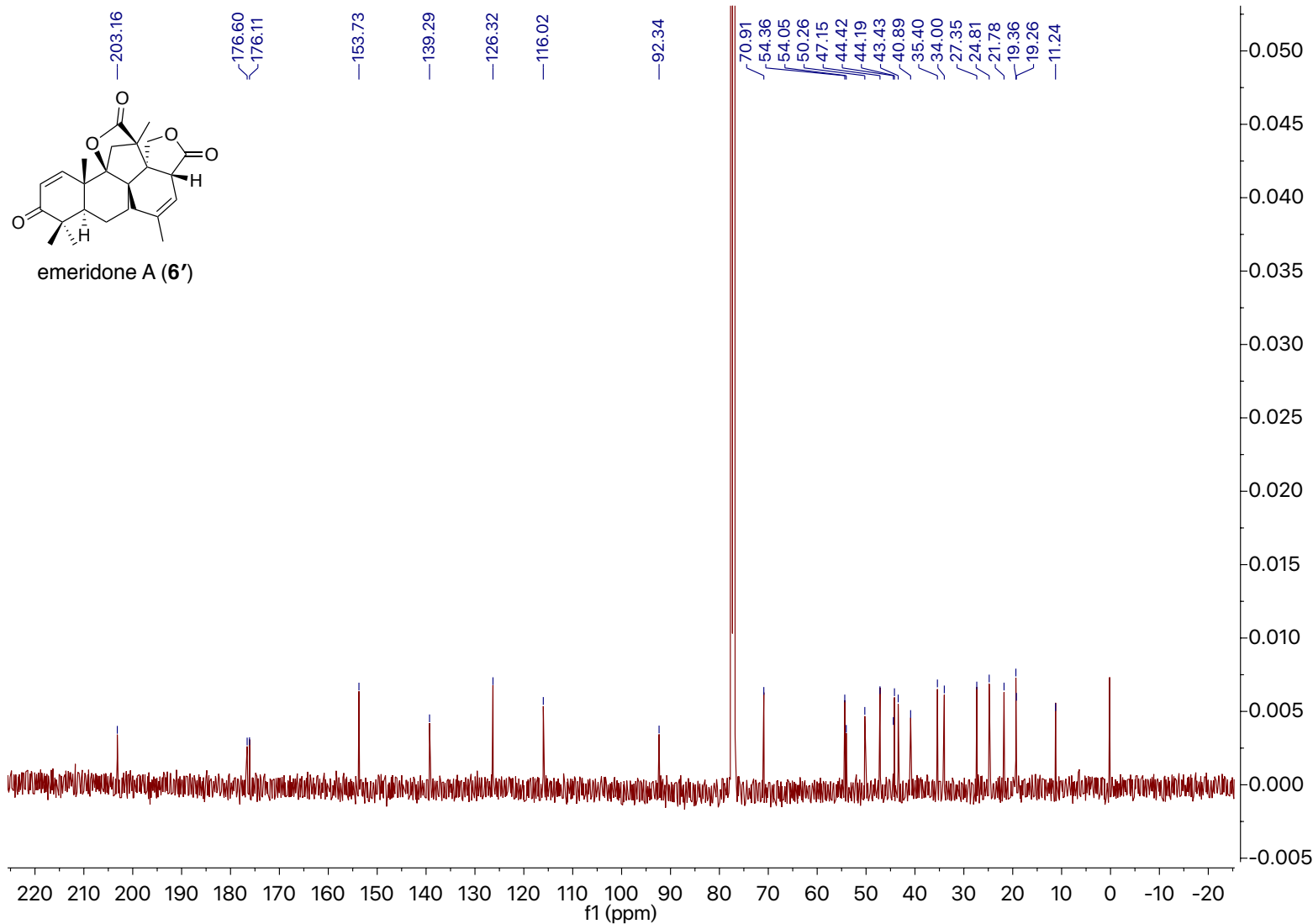

Figure S18. ${ }^{13} \mathrm{C}$ NMR spectrum of emeridone $\mathrm{A}\left(\mathbf{6}^{\prime}\right)$ in $\mathrm{CDCl}_{3}$ at $125 \mathrm{~Hz}$. 


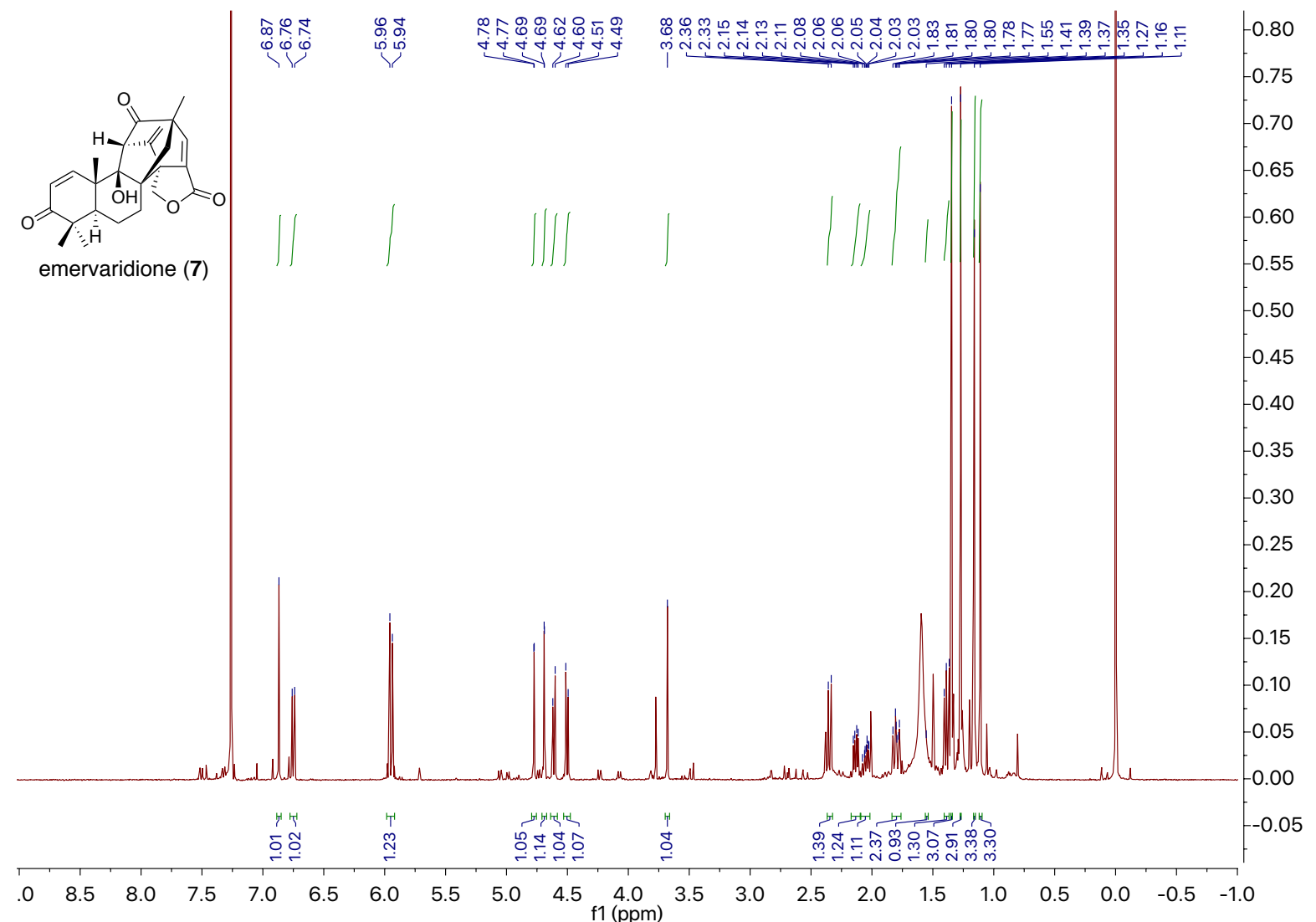

Figure S19. ${ }^{1} \mathrm{H}$ NMR spectrum of emervaridione (7) in $\mathrm{CDCl}_{3}$ at $500 \mathrm{~Hz}$.
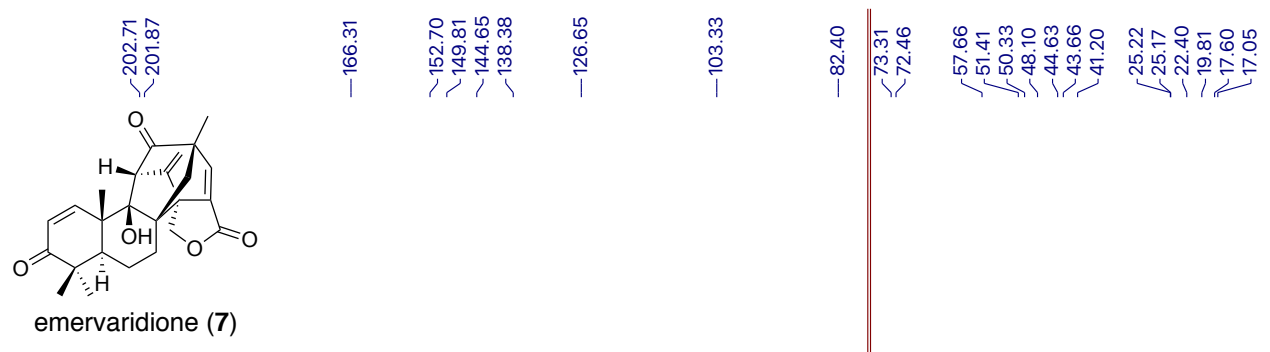

Figure S20. ${ }^{13} \mathrm{C}$ NMR spectrum of emervaridione (7) in $\mathrm{CDCl}_{3}$ at $125 \mathrm{~Hz}$. 


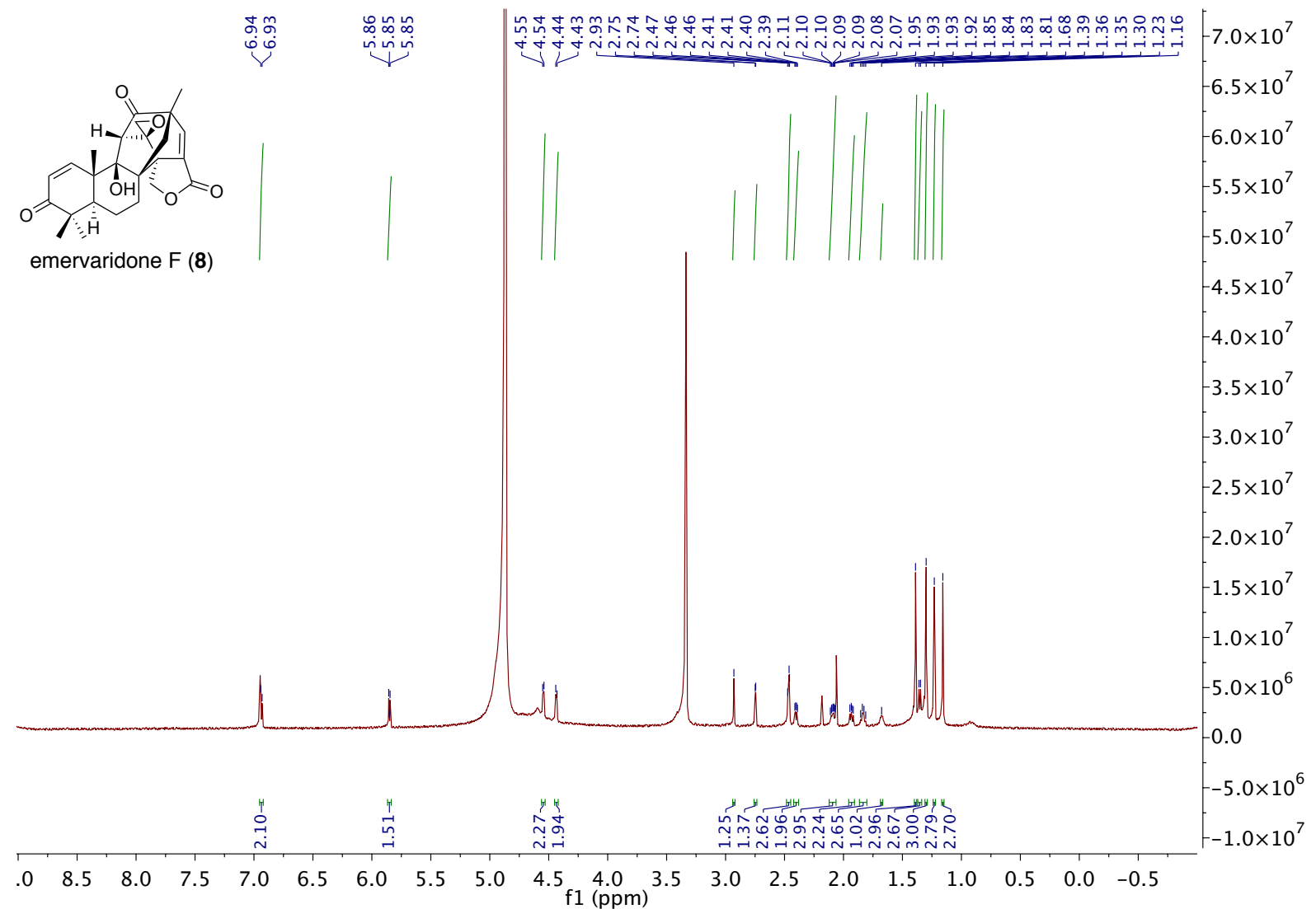

Figure S21. ${ }^{1} \mathrm{H}$ NMR spectrum of emeridone $\mathrm{F}(\mathbf{8})$ in $\mathrm{CD}_{3} \mathrm{OD}$ at $900 \mathrm{~Hz}$.
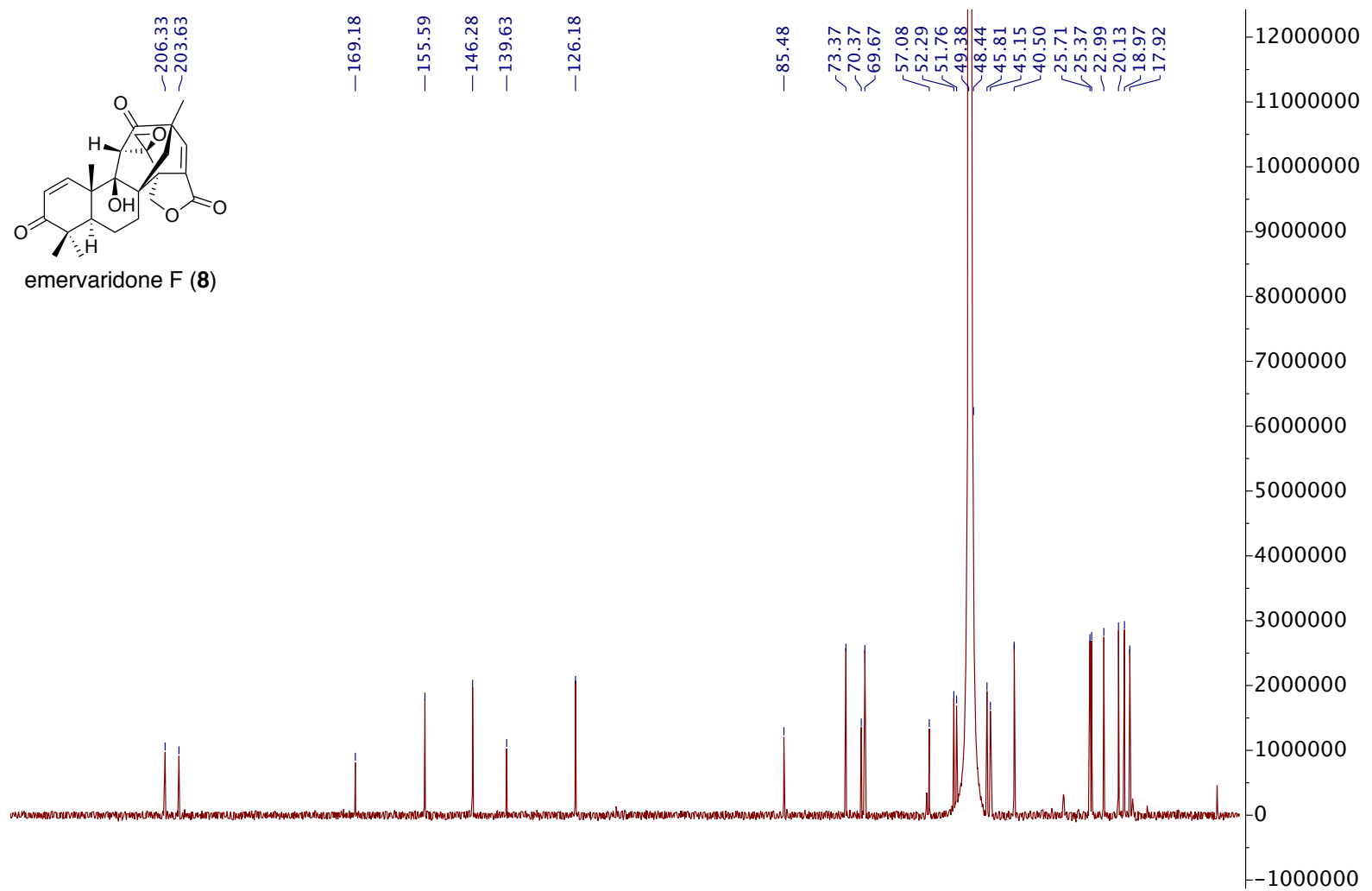

$\begin{array}{lllllllllllllllllllllllll}230 & 220 & 210 & 200 & 190 & 180 & 170 & 160 & 150 & 140 & 130 & 120 & 110 & 100 & 90 & 80 & 70 & 60 & 50 & 40 & 30 & 20 & 10 & 0\end{array}$

Figure S22. ${ }^{13} \mathrm{C}$ NMR spectrum of emeridone F (8) in $\mathrm{CD}_{3} \mathrm{OD}$ at $225 \mathrm{~Hz}$. 


\section{Supplementary References}

(1) He, Y.; Hu, Z.; Sun, W.; Li, Q.; Li, X.-N.; Zhu, H.; Huang, J.; Liu, J.; Wang, J.; Xue, Y.; Zhang, Y. Spiroaspertrione A, a bridged spirocyclic meroterpenoid, as a potent potentiator of oxacillin against methicillin-resistant Staphylococcus aureus from Aspergillus sp. TJ23. J. Org. Chem. 2017, 82, 31253131.

(2) Matsuda, Y.; Wakimoto, T.; Mori, T.; Awakawa, T.; Abe, I. Complete biosynthetic pathway of anditomin: Nature's sophisticated synthetic route to a complex fungal meroterpenoid. J. Am. Chem. Soc. 2014, 136, 15326-15336.

(3) Fujii, T.; Yamaoka, H.; Gomi, K.; Kitamoto, K.; Kumagai, C. Cloning and nucleotide sequence of the ribonuclease T1 gene (rntA) from Aspergillus oryzae and its expression in Saccharomyces cerevisiae and Aspergillus oryzae. Biosci., Biotechnol., Biochem. 1995, 59, 1869-1874.

(4) Kubodera, T.; Yamashita, N.; Nishimura, A. Transformation of Aspergillus sp. and Trichoderma reesei using the pyrithiamine resistance gene (ptrA) of Aspergillus oryzae. Biosci., Biotechnol., Biochem. 2002, 66, 404-406.

(5) Matsuda, Y.; Bai, T.; Phippen, C. B. W.; Nødvig, C. S.; Kjærbølling, I.; Vesth, T. C.; Andersen, M. R.; Mortensen, U. H.; Gotfredsen, C. H.; Abe, I.; Larsen, T. O. Novofumigatonin biosynthesis involves a non-heme iron-dependent endoperoxide isomerase for orthoester formation. Nat. Commun. 2018, 9, 2587.

(6) He, Y.; Hu, Z.; Li, Q.; Huang, J.; Li, X.-N.; Zhu, H.; Liu, J.; Wang, J.; Xue, Y.; Zhang, Y. Bioassayguided isolation of antibacterial metabolites from Emericella sp. TJ29. J. Nat. Prod. 2017, 80, 23992405.

(7) Li, Q.; Chen, C.; Cheng, L.; Wei, M.; Dai, C.; He, Y.; Gong, J.; Zhu, R.; Li, X.-N.; Liu, J.; Wang, J.; Zhu, H.; Zhang, Y. Emeridones A-F, a series of 3,5-demethylorsellinic acid-based meroterpenoids with rearranged skeletons from an endophytic fungus Emericella sp. TJ29. J. Org. Chem. 2019, 84, 1534-1541.

(8) Liangsakul, J.; Pornpakakul, S.; Sangvichien, E.; Muangsin, N.; Sihanonth, P. Emervaridione and varioxiranediol, two new metabolites from the endophytic fungus, Emericella variecolor. Tetrahedron Lett. 2011, 52, 6427-6430. 